\title{
Chemical Compositions in Modified Salinity Waterflooding of Carbonate
}

\section{Reservoirs - Experiment}

\author{
M.P. Yutkin
}

\author{
T.W. Patzek
}

April 23, 2021

\begin{abstract}
Modified or low-salinity waterflooding of carbonate oil reservoirs is of considerable economic interest because of potentially inexpensive incremental oil production. The injected modified brine changes the surface chemistry of the carbonate rock and crude oil interfaces and detaches some adhered crude oil. Composition design of the modified brine to enhance oil recovery is determined by labor-intensive trial-and-error laboratory corefloods. Unfortunately, limestone, which predominantly consists of aqueous-reactive calcium carbonate, alters injected brine composition by mineral dissolution/precipitation. Accordingly, the rock reactivity hinders rational design of the tailored brine to improve oil recovery. Previously, we presented a theoretical analysis of $1 \mathrm{D}$, single-phase brine injection into calcium carbonate-rock that accounts for mineral dissolution, ion exchange, and dispersion (Yutkin et al., 2021). Here we present the results of single-phase waterflood-brine experiments that verify the theoretical framework. We show that concentration histories eluted from Indiana limestone cores possess features characteristic of fast calcium carbonate dissolution, 2:1 ion exchange, and high dispersion. The injected brine reaches chemical equilibrium inside the porous rock even at injection rates higher than $1000 \mathrm{ft} /$ day. Ion exchange results in salinity waves observed experimentally, while high dispersion is responsible for long concentration history tails. Using the verified theoretical framework, we briefly explore how these processes modify aqueous-phase composition during the injection of designer brines into a calcium-carbonate reservoir. Because of high salinity of the initial and injected brines, ion exchange affects injected concentrations only in high surface area carbonates/limestones, such as chalks. Calcium-carbonate dissolution only affects aqueous solution $\mathrm{pH}$. The rock surface composition is affected by all processes.
\end{abstract}

\section{Keywords: Indiana Limestone, Dispersion, Ion-Exchange, Calcite Dissolution Rate, Mass Transfer}

\section{Introduction}

Modified brine composition floods may increment oil recovery at low cost, and consequently they have been studied quite intensively(Morrow and Buckley, 2011; Al-Shalabi and Sepehrnoori, 2016; Mahani et al., 2017; Hao et al., 2019; Katende and Sagala, 2019). Although first discovered with low-salinity waterfloods of crude oils from sandstone cores (Jadhunandan and Morrow, 1995), application to more plentiful carbonate rocks has shown similar recoveries (Zhang and 
Austad, 2006; Strand et al., 2006; Zhang et al., 2007; Yousef et al., 2011). In both rock types, decreasing salinity is not a necessary condition for improved recovery. Rather, the composition of the injected brine must be altered compared to that initially present in the medium (Austad et al., 2010, 2015; Collini et al., 2020). Although detailed molecular- and pore-level mechanism(s) are not known, there is some agreement that incremental oil production originates by altering rock wettability towards more water wet (Mahani et al., 2017; Katende and Sagala, 2019; Hao et al., 2019; Rücker et al., 2020). Apparently, modified injected brine changes the surface chemistry of the rock/brine and crude-oil/brine (i.e., COBR) interfaces to detach oil from rock surfaces (Jackson et al., 2016; Hu et al., 2018). Carefully tailored, specific brine packages are required to increment oil recovery. Brine design is currently accomplished by labor-intensive trial-and-error coreflooding experiments.

Modified-brine flooding of carbonate reservoirs presents additional challenges. In aqueous solution, calcite undergoes mineral dissolution/precipitation reactions that alter the injected brine composition. During advance of a waterflood through carbonate rock, brine composition adjusts to calcite dissolution/precipitation and, in turn, alters the surface chemistry of COBR interfaces. Ion exchange produces salinity and composition waves traveling through the porous rock (Yutkin et al., 2021). Dissolution/precipitation kinetics of minority reactive minerals like dolomite and anhydrite adds more complexity. Dispersion and stagnant micropore zones add further complication.

Design of modified-salinity waterfloods must account for the composition changes induced by contact with dissolving and ion-exchanging rock. Few authors account for reactive-rock compositional effects in displacement simulation (Qiao et al., 2015; Al-Shalabi et al., 2015; Pouryousefy et al., 2016; Farajzadeh et al., 2017). Previously, we presented a theoretical analysis of $1 \mathrm{D}$ single-phase brine injection into calcium carbonate-rock accounting for mineral reaction, ion exchange, and dispersion. Numerical solution is based on a widely available open-source code, PHREEQC (Charlton and Parkhurst, 2011; Parkhurst and Appelo, 2013), validated against analytical solutions for reactive transport, mass-transfer, ion exchange, and dispersion during flow through a carbonate porous medium. We capture all aqueous carbonate species, as well as surface charge densities and zeta potentials of calcium carbonate rock. Published reaction-rate and mass-transfer constants for aqueous calcium-carbonate dissolution elicit high Damköhler numbers and fast attainment of local equilibrium. Our theoretical analysis provides a tool to predict the effects of rock contact on tailored modified-brine waterflood compositions.

To verify our theoretical framework, we report here experimental single-phase waterflood-brine histories from Indianalimestone core plugs for several initial and injected sodium chloride/calcium chloride compositions in both loading and washout modalities. Comparison is then made to predicted behavior from our theoretical analysis. We confirm that carbonate-mineral dissolution achieves equilibrium directly upon brine injection even at high flow rates and in short cores and that ion exchange and dispersion play critical roles. Our findings emphasize the importance of understanding carbonate chemistry for interpretation of modified-salinity corefloods. Without insights on the processes occurring during advance of injected brine through a reactive porous rock, observed history data can be misinterpreted and the underlying physics and chemistries overlooked. Our proposed theory correctly captures aqueous ion-concentration histories emerging from a porous limestone. Moreover, we predict companion concentration profiles that are crucial for revealing possible oil-recovery mechanisms with low/modified/controlled salinity waterflooding, as well as for rational design of injected 


\section{Methods}

\subsection{Materials and Chemicals}

All flow experiments were performed on 1.5" by 3" Indiana limestone core plugs obtained from Kocurek Industries, Inc (Texas). Two different permeability cores used were used $\sim 25 \mathrm{mD}$ and $\sim 250 \mathrm{mD}$. Salt chemicals for the coreflood experiments were obtained from Fisher Scientific (reagent grade) and were used without additional treatment. Brine solutions were prepared with reverse-osmosis water further purified with a four-stage Milli-Q ADVANCE water system from Millipore $(\sigma$, conductivity $>18.2 \mathrm{M} \Omega \mathrm{cm}, \mathrm{TOC}=3 \mathrm{ppb})$.

\subsection{Liquid Saturation}

Prior to liquid-permeability measurements, core plugs were saturated with 1-mM $\mathrm{NaCl}$ brine. A dry core was loaded in a stainless-steel core holder (PC625014, MetaRock Laboratories, Texas) with a Viton rubber sleeve and confined to 500 psi. Confining pressure was maintained automatically during the experiments by an ISCO pump (100D, Teledyne ISCO, Nebraska). The core was evacuated and vacuum level was monitored with a high resolution digital pressure gauge (200M, DigiVac, New Jersey). After several hours, when the vacuum level reached 300 mTorr corresponding to evaporation of irreducible water, the core remained under vacuum for at least another 8 hours. The core inlet was then opened to a calibrated burette containing the saturating brine. This procedure guaranteed complete brine saturation and permitted volumetric measurement of brine porosity as reported in Tables $1-4$.

\subsection{Corefloods}

Displacement experiments were performed at room temperature in vertical geometry (top to bottom flow) with automatic confining pressure control set to 500 psi. Injection flow rates were set either at $5 \mathrm{~mL} / \mathrm{min}$ or at $50 \mathrm{~mL} / \mathrm{min}$ (i.e., at $140 \mathrm{ft} /$ day or at $\sim 1400 \mathrm{ft} /$ day frontal advance rate, respectively). Typical reservoir velocities are of the order of $1 \mathrm{ft} / \mathrm{day}$ (Masalmeh et al., 2014). However, we chose high flow rates to probe for the possible importance of calcite-dissolution kinetics which is gauged by the ratio of the dissolution rate constant divided by the frontal advance rate. Four pairs of replicated corefloods (i.e., loading and washout) were conducted on three separate core plugs (16 experiments in total).

Two brines were studied (A): $\mathrm{NaCl} \sim 10^{-3} \mathrm{M}$ and $(\mathrm{B}): \mathrm{NaCl} \sim 0.1 \mathrm{M}$. Both brines were devoid of calcium and each was at $\mathrm{pH}=5.6$ corresponding to environmental $\mathrm{CO}_{2}$ exposure. Two injection sequences were implemented: (1) saturation with brine A followed by displacement with brine B and (2) saturation with brine B followed by displacement with brine A. Note, these injection sequences were executed as separate experiments, but without core resaturation. Core equilibration with low-salinity brine A favors exchangeable surface calcium (generated by dissolution), whereas equilibration with highsalinity brine B favors low calcium surface occupancy. Accordingly, the first sequence corresponds to calcium unloading or washout, and the second sequence corresponds to calcium-exchanger loading (Pope et al., 1978; Yutkin et al., 2021, 
Appendix C). After initial brine saturation, each core plug was pre-flushed with at least 5 pore volumes (PV) of brine A or B, depending on the injection sequence chosen. Flow was switched to the second brine in the sequence for $5-6$ additional pore volumes, using a 4-way cross-over valve (SS-43YFS, Swagelok).

Core effluent samples were collected every $0.1-0.2 \mathrm{PV}(2-3 \mathrm{~mL})$. The mass of each collection vial was recorded; incremental volume was calculated from gravimetric data. After suitable aqueous dilution, chemical analyses for sodium and calcium were performed using ICP-OES (Model 7200-ES, Varian, Inc/Agilent). Chloride analyses were done by a colorimetric ferrocyanide method (Aquakem 250, Thermo Scientific). Because chloride ion does not participate in bulksolution or surface-reaction equilibria, it serves as an inert tracer. $\mathrm{pH}$ measurements were not performed due to small sample volumes.

\section{Tracer Pore Volume and Dispersion}

We conduct 4 pairs of single-phase corefloods on 3 separate core plugs, referred to below as experiments 1 through 4 , each replicated. Each coreflood pair consists of a calcium loading and unloading displacement. Data analysis for each displacement experiment starts with tracer behavior. After correction for dead volume of the apparatus, mass balance on the effluent chloride tracer concentration from the core plug determines the tracer liquid porosity, $\varphi$, using frontal-analysis chromatography as described in Appendix A. Results for the 4 coreflood pairs in both loading and washout sequences are summarized in Tables $1-4$. Agreement with the volumetric-determined porosities, $\varphi_{\text {brine }}$, from the core initial brine saturation is good.

Once frontal-analysis core porosity is established, tracer concentration histories are analyzed to determine the longitudinal dispersion coefficient $D_{L}$. Error standard deviations in the measured dispersion coefficient are listed in Tables 1 - 4. Fitting error is smaller the larger is the number of collection samples analyzed. Analytic solution to 1D tracer transport in porous media subject to Danckwerts boundary conditions gives the effluent concentration, $C_{L}$, as (Lapidus and Amundson, 1952; Danckwerts, 1953; Ogata and Banks, 1961; Hashimoto et al., 1964; Gupta and Greenkorn, 1974; Lake, 1989)

$$
\widetilde{C}(\tilde{t}, \tilde{x})=\frac{1}{2} \operatorname{erfc}\left[\frac{(\tilde{x}-\tilde{t})}{\sqrt{\tilde{t}}} \frac{\sqrt{P e_{L}}}{2}\right]+\frac{1}{2} \exp \left(P e_{L}\right) \operatorname{erfc}\left[\frac{(\tilde{x}+\tilde{t})}{\sqrt{\tilde{t}}} \frac{\sqrt{P e_{L}}}{2}\right]
$$

where $\widetilde{C}=\left(C_{L}-C_{0}\right) /\left(C_{\infty}-C_{0}\right)$ with subscript 0 and $\infty$ denoting initial and injected tracer concentrations respectively, $\tilde{t}=u t / \varphi L$ is PV injected, $\tilde{x}=x / L$ is dimensionless length (When $x=L$, the equation yields concentration history, when $0<x<1$, the equation yields concentration profiles), and $P e_{L}=u L / D_{L}$ is the longitudinal Peclét number. Example tracer histories from Indiana-limestone Core 1 are shown in Figure 1 (open squares) for exchanger loading (sequence 1) in Figure 1a and for exchanger unloading (sequence 2) in Figure 1b. Typical error bars shown in the legend indicate one standard deviation. Dashed lines in Figure 1 represent best fits of the experimental data to Equation 1. In obedience to Equation 1, measured tracer breakthrough histories are asymmetric about one pore volume due to the small measured longitudinal Péclet numbers and the corresponding large dispersion coefficients. Nevertheless, we find good fits for all 
tracer experiments interpreted in the same manner as in Figure 1. Tables $1-4$ illustrate that the fit dispersion coefficients are consistent in both loading and washout sequences.

Hydrodynamic dispersion coefficients obtained from our tracer-chromatography data (see Tables $1-4$ ) are notably larger than those for beadpacks, sandpacks, or sandstones (Perkins and Johnston, 1963; Delgado, 2006). Carbonates, however, are well known for their large dispersivities because of high heterogeneity (Gist et al., 1990; Bijeljic et al., 2011, 2013; Kurotori et al., 2019) with, for example, nested microporosities of ooids and porositons (Clerke et al., 2008). Few authors report hydrodynamic dispersion coefficients for Indiana limestone. The available list includes Gist et al. (1990), Vargas et al. (2013), and Singer et al. (2016). All experiments of these authors are at slower flow rates than we study except for those of Vargas et al. (2013) whose highest flow rate overlaps our lowest flow rate. Comparison to Vargas et al. (2013) suggests that our findings are reasonable.

\section{Dissolution Kinetics and Dispersion}

We explore calcite dissolution in experimental calcium-concentration histories. Calcium is not injected either during initial core saturation or during single-phase displacements. Yet, we consistently observe nonzero calcium concentrations in the effluent. Effluent calcium arises because of calcite dissolution during the initial 5 PV loading sequence. Final effluent calcium concentrations are different at different initial injected $\mathrm{NaCl}$ concentrations.

Figure 2 compares experimental (a) washout and (b) loading calcium histories obtained from Core 1. Symbols portray tracer (open squares) and calcium (open circles) concentration histories, each experiment replicated. Typical error bars are shown, as in the figures to follow. Pertinent parameters and injection-sequence concentrations are given in Table 1. Theorypredicted tracer history is represented by dashed lines based on the measured porosity and the fit dispersion coefficient (see Figure 1). Dotted, dot-dashed, and double dot-dashed lines give theoretical calcium histories corresponding to calcite dissolution kinetics with longitudinal dispersion. Calcium histories are calculated using the aqueous equilibrium speciation in Table 5 and the calcite dissolution reaction kinetics of (Yutkin et al., 2021, SI). The spreads in the concentration history in Figure 2 are controlled by dispersion, whereas the long-time concentration levels are controlled by dissolution-reaction rate and mass-transfer resistance.

The ambient-temperature dissolution rate constant of calcite is $k_{r x n}=10^{-5} \mathrm{~m} / \mathrm{s}$ (Morse and Arvidson, 2002) and the mass transfer coefficient at the $1400 \mathrm{ft} /$ day frontal advance rate is $k_{m t}=2.2510^{-4} \mathrm{~m} / \mathrm{s}$ (Rexwinkel et al., 1997, Fig. 2). For the flow conditions of Core 1, these coefficients correspond to reaction and mass-transfer Damköhler numbers of $D a_{r x n}=120$ and $D a_{m t}=2660$, respectively, where $D a_{r x n}=\varphi_{1} a_{V_{1}} k_{r x n} L / u$ and $D a_{m t}=\varphi_{1} a_{V_{1}} k_{m t} L / u$. In these definitions, $\varphi_{1}$ and $a_{V_{1}}$ are calcite mineral porosity and surface area per unit solid calcite volume, respectively. Appendix B summarizes the calculation of $\varphi_{1}$ and $a_{V_{1}}$ for each core. To illustrate the roles of reaction kinetic and mass transfer resistances, the reaction rate constant is lowered to $4.2 \times 10^{-9} \mathrm{~m} / \mathrm{s}$ (i.e., $D a_{\mathrm{rxn}}=0.05$ shown by dotted lines) and, likewise, the mass transfer coefficient is lowered to $10^{-6} \mathrm{~m} / \mathrm{s}\left(D a_{m t}=2.66\right.$ shown by double-dot-dashed lines $)$. Dotted and doubledot-dashed lines in Figure 2 are close or overlap confirming that mass-transfer Damköhler numbers greater than about unity play little role in calcium dissolution kinetics (Yutkin et al., 2021). Comparison of the dotted and dot-dashed lines 
in Figure 2 reveals that the reaction Damköhler number must fall well below unity before reaction kinetics plays a role in calcite dissolution. Once the reaction Damköhler number exceeds unity, local reaction equilibrium prevails throughout the core, except at very near the core inlet (Yutkin et al., 2018, 2021).

Reaction kinetics and dispersion adequately represent the long-time calcium experimental histories, with some underprediction in Figure 2b (and in Figures $6-8$ to follow). Calcite equilibrium chemistries in Table 5 are extensively documented, suggesting that Indiana-limestone core plugs contain minor calcium-dissolving minerals other than pure calcite. The discrepancy, however, is not major. Thus, the tabulated equilibrium reaction constants predict calcite dissolution in Indiana-limestone cores with no adjustable parameters. We conclude that calcite dissolution achieves local equilibrium with carbonate rock almost directly at the inlet face. Even in short cores at high frontal-advance rates, reaction rate and mass transfer resistances in carbonate rocks are negligible. Nevertheless, dissolution reaction with dispersion does not account for the breakthrough maximum in calcium concentration. The observed calcium-concentration maximum in Figure 2a, and its absence in Figure 2b, are not captured by calcite dissolution.

\section{$5 \quad$ Ion exchange and Dispersion}

To address the calcium maximum in Figure 2a, we hypothesize 2:1 equilibrium exchange of sodium and calcium ions on the carbonate-rock surface (Yutkin et al., 2021) or

$$
2>\mathrm{S}^{-} \mathrm{Na}^{+}+\mathrm{Ca}^{2+} \stackrel{K_{C a N a}}{\longleftrightarrow}>\mathrm{S}_{2}{ }^{-} \mathrm{Ca}^{2+}+2 \mathrm{Na}^{+}
$$

where $>\mathrm{S}^{-}$denotes a surface exchange site and $K_{\mathrm{CaNa}}$ is the exchange equilibrium constant (Yutkin et al., 2021, Appendix B). Equilibrium calcium uptake on the rock surface then obeys the expression

$$
\frac{y_{\mathrm{Ca}^{2+}}}{\left(1-y_{\mathrm{Ca}^{2+}}\right)^{2}}=\left[\frac{K_{\mathrm{CaNa}} n_{C E C}}{C_{\mathrm{Cl}^{-}}}\right] \frac{x_{\mathrm{Ca}^{2+}}}{\left(1-x_{\mathrm{Ca}^{2+}}\right)^{2}}
$$

where $y_{\mathrm{Ca}^{2+}}=2 n_{\mathrm{Ca}^{2+}} / n_{C E C}, n_{C E C}=2 n_{\mathrm{Ca}^{2+}}+n_{\mathrm{Na}^{+}}$is the cation exchange capacity expressed in mole per $\mathrm{m}^{2}$ surface area, $x_{\mathrm{Ca}^{2+}}=2 C_{\mathrm{Ca}^{2+}} / C_{\mathrm{Cl}^{-}}, C_{\mathrm{Cl}^{-}}=2 C_{\mathrm{Ca}^{2+}}+C_{\mathrm{Na}^{+}}$is the total chloride concentration neutralizing calcium and sodium ions in $\mathrm{mol} / \mathrm{m}^{3}$, and $K_{\mathrm{CaNa}}$ is the ion-exchange equilibrium constant with units of $\mathrm{m}^{-1}$.

In porous-media displacement processes with ion exchange, it is convenient to replace the surface-area units in the definition of $n_{C E C}$ to pore volume units (Pope et al., 1978) giving a cation exchange capacity of

$$
C E C=n_{C E C} a_{V_{2}} \varphi_{2} / \varphi
$$

with $C E C$ expressed units of mol/L pore volume. $a_{V_{2}}$ in Equation 4 is the exchange mineral surface area per mineral volume, $\varphi_{2}$ is the volume of the exchange mineral per core volume, and $\varphi$ is rock porosity.

Equation 3 applies most directly to clay-type reservoir minerals (Soudek, 1985; Pope et al., 1978). Application to the aqueous-calcite surface is more complicated (Yutkin et al., 2018, and others). The calcite surface consists of many 
ion-exchange and charging reactions as enumerated by the surface complexation model (SCM) in Table 6 . Reactions $S_{5}$ and $S_{6}$ in Table 6 correspond to calcium/sodium ion exchange in Equation 3. However, reactions $S_{1}$ through $S_{4}$ occur simultaneously on calcite rock as dictated by local calcite-equilibrated pore concentrations.

To assess the validity of Equation 3 for calcite surfaces, we implement the surface complexation model of Table 6 (Yutkin et al., 2018). In the SCM calculations, we set the initial brine solution as an aqueous mixture of $\mathrm{NaCl}_{1} \mathrm{CaCl}_{2}$, and environmental dissolved $\mathrm{CO}_{2}$. Given the initial-brine concentrations, we equilibrate that solution with calcite per the equilibrium chemistries in Table 6 . The resulting equilibrated brine then sets the bulk aqueous concentrations to establish the SCM surface-species concentrations following Table 6. Figure 3 compares the sodium/calcium ion exchange isotherm predicted from the SCM (filled squares) with those predicted by Equation 3 for a fixed cation exchange capacity and for four different exchange equilibrium constants. Best fit of Equation 3 to SCM predictions in Figure 3 (filled squares) is successful giving an exchange equilibrium constant near $10^{7} \mathrm{~m}^{-1}$ and a cation exchange capacity of 1.7 sites $/ \mathrm{nm}^{2}$. The literature lattice surface site density for (104) calcite surface is 5 sites $/ \mathrm{nm}^{2}$ (Yutkin et al., 2018). Due to the occupancy of other surface species in reactions $S_{1}$ through $S_{4}$ of Table 6 , however, less than a half of the total available sites are available for sodium/calcium ion exchange on calcite. The SCM isotherm (filled squares) does not extend to zero calcium concentration because equilibration of the aqueous solution with calcite mineral always demands finite aqueous calcium concentrations. This restriction also explains the narrow range of calcium exchanger loadings on calcite mineral.

We find that Equation 3 provides adequate representation of calcium/sodium ion exchange on calcite. However, clays and minor minerals in Indiana-limestone cores may also contribute to sodium/calcium ion exchange. Here, all ion-exchange minerals are lumped into a single 2:1 exchange isotherm according to Equation 3. In addition, the individual cores studied have differing porosities and permeabilities and, hence, differing surface areas for ion exchange. We express the cation exchange capacity for each individual core according to Equation 4. To establish $a_{V_{2}}$ and $\varphi_{2}$ necessary to convert exchangecapacity units, we assume that calcite mineral is in excess (i.e., $\varphi_{2}=\varphi_{1}$ ) and utilize the Carman-Kozeny expression for $a_{V_{2}}$ (see Appendix B). Resulting values are listed in Tables $1-4$. Because of the differing mineralogy of each core, we adjust $n_{C E C}$ in the three different cores plugs. To reduce the number of adjustable model parameters, we keep the same equilibrium exchange constant for each core of $p K_{\mathrm{CaNa}}=-5.8$ from Figure 3.

Figure 4 presents frontal-displacement theory calculations for calcium (a) unloading and (b) loading experiments with Core 1 for ion exchange and dispersion but with no rock dissolution. A skeleton of chromatographic ion-exchange waves is seen. Namely, in Figure 4a, a high calcium-concentration washout zone is apparent with a desorption-spreading tail (Pope et al., 1978; Yutkin et al., 2021, Appendix C). Conversely in Figure 4b, a low calcium-concentration loading zone with a sharpening tail (Pope et al., 1978; Yutkin et al., 2021, Appendix C) is faintly visible. In both displacement scenarios, the ion-exchange waves are significantly smeared by large longitudinal dispersion. Two equilibrium exchange constants are shown in Figure 4 by the dotted and dot-dashed lines, each with the best-fit dispersion coefficient listed in Table 1 . The cation exchange capacity is fixed from Figure 3 at $1.4 \times 10^{-3} \mathrm{M}$ (i.e., 1.74 sites $/ \mathrm{nm}^{2}$ ). Limestone Core- 1 exchange capacity is significantly lower than that of Berea sandstone (Pope et al., 1978; Hill and Lake, 1978). With ion-exchange/dispersion theory in Figure 4a, the calcium maximum now appears as does a shallow minimum in Figure $4 \mathrm{~b}$. With the $p K_{\mathrm{CaNa}}$ fixed, 
the cation exchange capacity $(C E C)$ controls the washout peak height. We fit the $C E C$ to the maximum in the washout history giving $\sim 3 \times 10^{-3} \mathrm{~mol} / \mathrm{L}$. Similarly obtained ion-exchange parameters for each experimental displacement pair are listed in Tables $1-4$.

Although ion exchange without calcite dissolution explains the calcium concentration peak and valley in Figures 4 (a) and (b), respectively, it does not explain the calcium history at large throughputs. Apparently, inclusion of both ion exchange and rock dissolution in the displacement model are required.

\section{Dissolution Reaction, Ion exchange and Dispersion}

We consider finally the combined effects of dissolution reaction kinetics, ion exchange, and longitudinal dispersion (Yutkin et al., 2021). Experimental washout and loading histories in Figure 5 are those from Core 1 and, thus, are identical to those in Figures 2 and 4. Theory parameters are highlighted in Table 1. All parameters have been previously determined from the analyses underscoring Figures $2-4$. To illustrate the comparative roles of reaction kinetics and ion exchange, theory calculations are shown for a low aphysical value of the reaction Damköhler number (i.e., $\left.D a_{r x n}=0.05\right)$ and cation exchange capacity (i.e., $C E C=0$ ).

Only the combined dissolution/ion-exchange/dispersion theory captures the experimental behavior in Figure 5. After peaking in Figure 5a, the calcium concentration slowly falls to the calcite equilibrated value, which would not be possible without fast dissolution. The double-dot dashed line shows the model with ion exchange but slow dissolution (i.e., $k_{r x n}$ is 1000 times smaller than that reported by Morse and Arvidson (2002)). The final predicted equilibrium calcium concentration in Figure 5, approximately $0.225 \mathrm{mM}$, is not reached until between 3 and 4 injected pore volumes. The long tail observed in Figure 5 arises partly from the self-spreading of washout ion exchange but mostly from the large hydrodynamic dispersion. The slowly decaying calcium history in Figure 5a is well captured by theory.

Figure 5b compares numerical and experimental results for exchanger loading of Core 1. Clearly again, slow dissolution (double-dot-dashed line) and no ion exchange (dot-dashed line), each including dispersion fail to capture the loading history. The combined theory (solid line) represents the measured calcium history adequately. We stress that only the dispersion coefficient and the cation exchange capacity are adjusted in Figures $1-5$. Reaction and mass transfer Damköhler numbers are large so that local equilibrium prevails. Accordingly, fitting the precise dissolution rate and mass transfer coefficients is unnecessary. The cation exchange capacity follows from the SCM in Table 6 and Equation 4 with evaluation of the rock specific surface area outlined in Appendix B.

Figures $6-8$ summarize similar theory and experiment for Cores 2 and 3. Experimental conditions are listed in Tables 2 - 4. Core 2 has a much lower permeability and, hence, higher specific surface area than that of Core 1 . Additionally, the flow rate used for the washout/loading displacement is 10 times smaller than that used in Core 1. Experiments 3 and 4 (Tables 3 and 4) utilize Core 3 in sequence at the two different flow rates of Cores 1 and 2, respectively. All displacement experiments are continued for 6 PV.

As above, we first analyze chloride-tracer breakthrough curves (open squares and triangles). This is justified both experimentally by history shape and theoretically by the absence of chloride ion in the surface ion-complexing reactions 
in the SCM of Table 6. Sodium histories mostly follow chloride histories because of the high concentration of injected sodium chloride and the relative low $C E C$ of Indiana limestone. Sodium and chloride-ion histories deviate somewhat from each other due to sodium-ion measurement error We rely on chloride-ion analyses for porosity and dispersion-coefficient determination in Figures $6-8$. Best-fit longitudinal Péclet numbers in Figure 6 for unloading and loading experiments (1.73 and 2.05 respectively, in Table 2) are in good agreement with each other.

The calcium history in Figure 6a is significantly different from that in Figure 5a (and from those in Figures 7a and 8a to follow) in that the peak calcium concentration is much higher. One reason is the higher specific surface area of Core 2 increasing the ion-exchange capacity. This alone, however, may not completely explain the factor of 10 increase in $C E C$ necessary to fit the calcium peak height in Figure 6a. We hypothesize that Core 2, and Core 3 to follow, contain other 2:1 calcium/sodium exchanging minerals that we lump with calcite ion exchange. The $C E C$ s in Figures $6-8$ are best fit with the equilibrium exchange constant held constant and equal to that in Figures $2-5$.

Concentrations histories in Figures 7 and 8 (Experiments 3 and 4) were obtained from the same core (Core 3) but at different flow rates $(50 \mathrm{~mL} / \mathrm{min}$ and $5 \mathrm{~mL} / \mathrm{min}$, respectively), so we discuss them together. The traits of the calcium histories in Figure 7 are similar to those in Figure 5. Obtained Péclet numbers are in good agreement at 4 and 2 for unloading and loading experiments, respectively (see Table 3).

Likewise, calcium concentration histories in Figure 8 share similar features with Figures 5 - 7. The most notable distinctions are the calcium peak heights during unloading and the valley depths during unloading. Thus, similar to Figure 6, the best-fit $C E C$ at the slower flow rate in Figure 8 is $1.5-3$ times higher than that in Figure 7 . The same observation was made for Figures 5 and 6: slower flows demand higher best-fit $C E C$ s. Because Figures 7 and 8 arise from the same core plug (Core 3), however, differing amounts of minority cation-exchanging minerals cannot be the explanation. One possibility is that minority exchanging minerals are distributed in relatively flow-inaccessible locations. Aqueous ion diffusion may be necessary to reach the exchange sites. Diffusion-limited ion exchange manifests at lower flow rates. Nevertheless, the discrepancy is not major. Overall, agreement between theory and experiment is remarkable, especially when only the $C E C$ is adjusted in each figure with physically reasonable values.

\section{Discussion}

We have carefully validated our approach to modeling and understanding calcite concentration histories obtained from Indinana-limestone core plugs during single phase waterflooding Yutkin et al. (2021). The experimentally observed effluent calcium concentrations can only be explained by the synergistic effect of fast dissolution, ion exchange on calcite and other mineral surfaces, and large dispersion. However, the experimental brines used for our model validations, are far from those employed in modified salinity flooding. In this section, we apply our model to higher salinity brines of a more practical composition and demonstrate how the above chemical processes affect the brine composition in low salinity waterflood.

Low salinity waterflooding of a reservoir corresponds to our second injection sequence discussed above i.e. for loading, which is shown in panels (b) of Figures 5-8. Reservoirs have long traverse injection lengths, so we increase Péclet numbers accordingly while neglecting $D_{L}$ dependence on length and velocity. We use the $C E C$ from our experiments. 
Figure 9 shows the predicted concentration profile (a) and concentration history (b) for low salinity waterflooding of Indiana limestone. The initial brine present in the core has a high salinity of $1.5 \mathrm{M} \mathrm{Na}^{+}, 2.5 \mathrm{M} \mathrm{Cl}^{-}$, and $0.5 \mathrm{M} \mathrm{Ca}^{2+}$ and

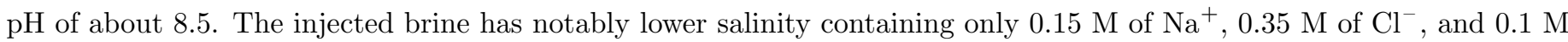
of $\mathrm{Ca}^{2+}$, and a pH of 7 . Figure 9a corresponds to $0.5 \mathrm{PV}$ injected into the core. The concentration plateaus to the right of $0.5 \mathrm{PV}$ designate those initially present in the core; with the exception of $\mathrm{pH}$, concentration plateaus to the left of 0.5 PV designate those injected. The spread of the concentrations is due to dispersion. Calcite rock dissolution changes the injected $\mathrm{pH}$ by about two orders of magnitude. Because of fast rock dissolution, the $\mathrm{pH}$ attains new equilibrium values almost instantaneously. No effects other than rock dissolution and dispersion are observed in the concentration profiles. Even if ion exchange exists, its effect is so small that it does not influence the concentration history in Figure $9 \mathrm{~b}$.

The $C E C$ of Indiana limestone in Figure 9 is too low to cause notable effects at such high ion concentrations. However, higher surface area carbonates, such as chalks, can alter the injected brine composition. Figure 10 shows concentration profile (a) and concentration history (b) for low salinity waterflooding of a Norwegian chalk (Puntervold et al., 2007, 2009). Chalk cores have very high porosity and very low permeability increasing the chalk exchange capacity by several orders of magnitude compared to Indiana limestone. We increased the $C E C$ by 20 in our calculations times to simulate the exchange capacity of a chalk porous rock. Figure 10a shows the predicted profile at 0.5 pore volume. Concentration plateaus to the right of $0.5 \mathrm{PV}$ designate concentrations initially present in the core. With the exception of $\mathrm{pH}$, concentration plateaus to the left of 0.5 PV designate those injected. Spreading of the concentrations is again due to dispersion, and calcite rock dissolution again changes the injected brine $\mathrm{pH}$ significantly. Calcium concentration fall directly behind $0.5 \mathrm{PV}$ due to ion exchange on the calcium carbonate surface. In Figure 10b, this effect translates through the core and for a quarter of pore volume almost devoids the emanating brine of calcium. We conclude that high-surface-area carbonates can significantly alter injected brine composition even at high salinities.

Salinity waves caused by ion exchange also shift calcite-rock surface chemical equilibrium. Figure 11 corresponds to Figure 10 for the high-surface-area chalk, but now with the calcite surface charge density in the $\beta$-plane listed in Figure 11a. In Figure 11a concentration plateaus to the right of $0.5 \mathrm{PV}$ designate concentrations initially present in the core. With the exception of $\mathrm{pH}$, concentration plateaus to the left of $0.5 \mathrm{PV}$ designate those injected. All the concentrations in Figure 11a, except the $\mathrm{pH}$, are replicated from Figure 10a. The gray dot-dashed line plots $\sigma_{\beta}$. Surface charge density is positive in the entire column and follows the tracer front and step concentration change. However, directly behind the tracer front in the region devoid of calcium, the charge density falls abruptly from 1 to $0.6 \mu \mathrm{C} \mathrm{cm}^{-2}$ and then rebounds to about $0.75 \mathrm{\mu} \mathrm{cm}^{-2}$. Along the traverse of the tracer front, the region with the lowest $\sigma_{\beta}$ broadens following the broadening of the low calcium concentration region. In this example simulation, $\sigma_{\beta}$ does not reverse sign. Nevertheless, this is a significant change in $\sigma_{\beta}$ and surface ionic composition during the modified salinity waterflood.

\section{Conclusions}

This work presents experimental effluent concentration histories for reactive transport, mass transfer, ion exchange, and dispersion during single-phase flow through Indiana-limestone core plugs. Experiments are well-matched by our previously 
published theory using only one fit parameter, the cation exchange capacity (Yutkin et al., 2021). We successfully lump the core mineralogy into pure calcium carbonate. More complex systems with mixed minerals, temperature effects, presence of crude oil and $\mathrm{CO}_{2}$ etc require more detailed investigation.

We demonstrate that concentration histories eluting from Indiana-limestone cores possess features characteristic of fast calcium carbonate dissolution, 2:1 ion-exchange on calcium carbonate or clay surface, and high dispersion. Experimentally observed histories can only be explained when all three effects are accounted for.

In our experiments, calcite dissolution is almost instantaneous. The injected brine achieves local equilibrium with the core material even at high injection rates, up to $1000 \mathrm{ft} /$ day. Ion exchange in Indiana-limestone cores follows a classical 2:1 ion-exchange isotherm. The cation exchange capacity can be found using calcite surface complexation modeling (SCM) that accounts for adsorption sites taken up by other ions. Indiana limestone, with other limestones, exhibits a highly heterogeneous pore structure. The result is high dispersion and long tails in concentration histories. Because of porestructure heterogeneity, some pores are apparently less accessible than others. Pore surfaces not observable at high flow rates can be interrogated at low flow rates, which results in experimentally higher cation exchange capacities than that predicted from surface SCM.

Finally, we explore the effect of ion exchange and calcite dissolution on injected brine compositions during low salinity waterfloods. A low-salinity injection scheme corresponds to washout of ions from a calcium carbonate surface. Because of high salinity of the in-situ (250000 ppm) and injected (50000 ppm) brines, ion exchange with the cation exchange capacity measured in our experiments induces virtually no effect on bulk ionic concentrations. Calcite dissolution only affects $\mathrm{pH}$, while ion concentrations change negligibly. However, chalks with orders higher exchange capacity appreciably change injected concentrations. This change in turn changes $\sigma_{\beta}$ and the surface composition of calcite, which if unaccounted can negatively affect efficiency of low salinity waterfloods.

\section{Acknowledgments}

MPY thanks Dr. Sirisha Kamireddy for performing chemical analysis.

\section{Declarations}

Funding This work was supported from baseline research funding to prof. Tadeusz Patzek. Partial support was provided by Saudi Aramco as project \#3899.

Conflicts of interest/Competing interests The authors declare no conflict of interests

Availability of data and material The experimental data sets are available from electronic supplementary information

Code availability We are working on making the code available to the public through github. 
Authors' contributions All authors contributed to the study conception and design. Material preparation, data collection and analysis were performed by Dr. Maxim Yutkin and partially by Dr. Sirisha Kamireddy (chemical analysis, acknowledged above). The first draft of the manuscript was written by Maxim Yutkin and all authors commented on previous versions of the manuscript. All authors read and approved the final manuscript.

Ethics approval Not applicable

Consent to participate Not applicable

Consent for publication Not applicable

\section{References}

Al-Shalabi EW, Sepehrnoori K (2016) A comprehensive review of low salinity/engineered water injections and their applications in sandstone and carbonate rocks. Journal of Petroleum Science and Engineering 139:137-161, DOI 10. 1016/j.petrol.2015.11.027

Al-Shalabi EW, Sepehrnoori K, Pope G (2015) Geochemical Interpretation of Low-Salinity-Water Injection in Carbonate Oil Reservoirs. SPE Journal 20(06):1212-1226, DOI 10.2118/169101-PA

Austad T, Rezaeidoust A, Puntervold T (2010) Chemical Mechanism of Low Salinity Water Flooding in Sandstone Reservoirs. Spe 129767:19-22, DOI 10.2118/129767-MS

Austad T, Shariatpanahi SF, Strand S, Aksulu H, Puntervold T (2015) Low Salinity EOR Effects in Limestone Reservoir Cores Containing Anhydrite: A Discussion of the Chemical Mechanism. Energy and Fuels 29(11):6903-6911, DOI 10.1021/acs.energyfuels.5b01099

Bijeljic B, Mostaghimi P, Blunt MJ (2011) Signature of non-fickian solute transport in complex heterogeneous porous media. Physical Review Letters 107(20):204502, DOI 10.1103/physrevlett.107.204502

Bijeljic B, Mostaghimi P, Blunt MJ (2013) Insights into non-fickian solute transport in carbonates. Water Resources Research 49(5):2714-2728, DOI 10.1002/wrcr.20238

Bird R, Stewart W, Lightfoot E (2007) Transport Phenomena. Wiley International edition, Wiley

Charlton SR, Parkhurst DL (2011) Modules based on the geochemical model phreeqc for use in scripting and programming languages. Computers \& Geosciences 37:1653-1663, DOI 10.1016/j.cageo.2011.02.005

Clerke E, W Mueller H, Craig Phillips E, Y Eyvazzadeh R, H Jones D, Ramamoorthy R, Srivastava A (2008) Application of thomeer hyperbolas to decode the pore systems, facies and reservoir properties of the upper jurassic arab d limestone, ghawar field, saudi arabia: A "rosetta stone" approach. GeoArabia 13 
Collini H, Li S, Jackson MD, Agenet N, Rashid B, Couves J (2020) Zeta potential in intact carbonates at reservoir conditions and its impact on oil recovery during controlled salinity waterflooding. Fuel 266:116927, DOI 10.1016/j.fuel. 2019.116927

Danckwerts P (1953) Continuous flow systems. Chemical Engineering Science 2(1):1-13, DOI 10.1016/0009-2509(53) $80001-1$

Delgado JM (2006) A Critical Review of Dispersion in Packed Beds. Heat and Mass Transfer/Waerme- und Stoffuebertragung 42(4):279-310, DOI 10.1007/s00231-005-0019-0

Farajzadeh R, Guo H, van Winden J, Bruining J (2017) Cation exchange in the presence of oil in porous media. ACS Earth Space Chem 1(2):101-112, DOI 10.1021/acsearthspacechem.6b00015

Gist GA, Thompson AH, Katz AJ, Higgins RL (1990) Hydrodynamic dispersion and pore geometry in consolidated rock. Physics of Fluids A: Fluid Dynamics 2(9):1533-1544, DOI 10.1063/1.857602

Gupta SP, Greenkorn RA (1974) Determination of Dispersion and Nonlinear Adsorption Parameters for Flow in Porous Media. Water Resources Research 10(4):839-846, DOI 10.1029/WR010i004p00839

Hao J, Mohammadkhani S, Shahverdi H, Esfahany MN, Shapiro A (2019) Mechanisms of smart waterflooding in carbonate oil reservoirs - a review. Journal of Petroleum Science and Engineering 179:276-291, DOI 10.1016/j.petrol.2019.04.049

Hashimoto I, Deshpande KB, Thomas HC (1964) Peclet numbers and retardation factors for ion exchange columns. Industrial \& Engineering Chemistry Fundamentals 3(3):213-218, DOI 10.1021/i160011a007

Hill H, Lake L (1978) Cation Exchange in Chemical Flooding: Part 3 - Experimental. Society of Petroleum Engineers Journal 18(06):445-456, DOI 10.2118/6770-PA

Hu X, Yutkin MP, Hassan S, Wu J, Prausnitz J, Radke C (2018) Calcium ion bridging of aqueous carboxylates onto silica: Implications for low-salinity waterflooding. Energy Fuels 33(1):127-134, DOI 10.1021/acs.energyfuels.8b03366

Jackson MD, Al-Mahrouqi D, Vinogradov J (2016) Zeta potential in oil-water-carbonate systems and its impact on oil recovery during controlled salinity water-flooding. Sci Rep 6(1), DOI 10.1038/srep37363

Jadhunandan PP, Morrow NR (1995) Effect of Wettability on Waterflood Recovery for Crude-Oil/Brine/Rock Systems. SPE Reservoir Engineering 10(1):40-46, DOI 10.2118/22597-pa

Katende A, Sagala F (2019) A critical review of low salinity water flooding: Mechanism, laboratory and field application. Journal of Molecular Liquids 278:627-649, DOI 10.1016/j.molliq.2019.01.037

Kurotori T, Zahasky C, Hejazi SAH, Shah SM, Benson SM, Pini R (2019) Measuring, imaging and modelling solute transport in a microporous limestone. Chemical Engineering Science 196:366-383, DOI 10.1016/j.ces.2018.11.001

Lake L (1989) Enhanced oil recovery. Prentice Hall 
Lapidus L, Amundson NR (1952) Mathematics of adsorption in beds. vi. the effect of longitudinal diffusion in ion exchange and chromatographic columns. The Journal of Physical Chemistry 56(8):984-988, DOI 10.1021/j150500a014

Mahani H, Menezes R, Berg S, Fadili A, Nasralla R, Voskov D, Joekar-Niasar V (2017) Insights into the impact of temperature on the wettability alteration by low salinity in carbonate rocks. Energy Fuels 31(8):7839-7853, DOI 10.1021/acs.energyfuels.7b00776

Masalmeh SK, Sorop T, Suijkerbuijk BM, Vermolen EC, Douma S, van del Linde H, Pieterse S (2014) Low salinity flooding: Experimental evaluation and numerical interpretation. IPTC, DOI 10.2523/iptc-17558-ms

Morrow N, Buckley J (2011) Improved Oil Recovery by Low-Salinity Waterflooding. Journal of Petroleum Technology 63(5):106-112, DOI 10.2118/129421-JPT

Morse JW, Arvidson RS (2002) The Dissolution Kinetics of Major Sedimentary Carbonate Minerals. Earth-Science Reviews 58(1-2):51-84, DOI 10.1016/S0012-8252(01)00083-6

Ogata A, Banks RB (1961) A solution of the differential equation of longitudinal dispersion in porous media. Tech. rep., DOI $10.3133 / \mathrm{pp} 411 \mathrm{~A}$

Parkhurst DL, Appelo CAJ (2013) Description of input and examples for PHREEQC version 3-A computer program for speciation, batch-reaction, one-dimensional transport, and inverse geochemical calculations. URL https://pubs. usgs . $\mathrm{gov} / \mathrm{tm} / 06 / \mathrm{a} 43$

Perkins T, Johnston O (1963) A Review of Diffusion and Dispersion in Porous Media. Society of Petroleum Engineers Journal 3(01):70-84, DOI 10.2118/480-PA

Pope G, Lake L, Helfferich F (1978) Cation Exchange in Chemical Flooding: Part 1-Basic Theory Without Dispersion. Society of Petroleum Engineers Journal 18(06):418-434, DOI 10.2118/6771-PA

Pouryousefy E, Xie Q, Saeedi A (2016) Effect of multi-component ions exchange on low salinity eor: Coupled geochemical simulation study. Petroleum 2(3):215-224, DOI 10.1016/j.petlm.2016.05.004

Puntervold T, Strand S, Austad T (2007) Water flooding of carbonate reservoirs: effects of a model base and natural crude oil bases on chalk wettability. Energy Fuels 21(3):1606-1616, DOI 10.1021/ef060624b

Puntervold T, Strand S, Austad T (2009) Coinjection of seawater and produced water to improve oil recovery from fractured north sea chalk oil reservoirs. Energy Fuels 23(5):2527-2536, DOI 10.1021/ef801023u

Qiao C, Johns R, Li L, Xu J (2015) Modeling low salinity waterflooding in mineralogically different carbonates. In: Day 3 Wed, September 30, 2015, SPE, DOI 10.2118/175018-ms

Rexwinkel G, Heesink A, Van Swaaij W (1997) Mass Transfer in Packed Beds at Low Peclet Numbers—wrong Experiments or Wrong Interpretations? Chemical Engineering Science 52(21-22):3995-4003, DOI 10.1016/S0009-2509(97)00242-X 
Rücker M, Bartels WB, Garfi G, Shams M, Bultreys T, Boone M, Pieterse S, Maitland G, Krevor S, Cnudde V, Mahani H, Berg S, Georgiadis A, Luckham P (2020) Relationship between wetting and capillary pressure in a crude oil/brine/rock system: From nano-scale to core-scale. Journal of Colloid and Interface Science 562:159-169, DOI 10.1016/j.jcis.2019. 11.086

Singer P, Mitchell J, Fordham E (2016) Characterizing dispersivity and stagnation in porous media using nmr flow propagators. Journal of Magnetic Resonance 270:98-107, DOI 10.1016/j.jmr.2016.07.004

Soudek A (1985) A Site-Binding Model for Multicomponent Ion-Exchange on Montmorillonite. PhD thesis, University of California

Strand S, Høgnesen EJ, Austad T (2006) Wettability alteration of carbonates - effects of potential determining ions $\left(\mathrm{Ca}_{2}{ }^{+}\right.$and $\left.\mathrm{SO}_{4}{ }^{2-}\right)$ and temperature. Colloids and Surfaces A: Physicochemical and Engineering Aspects 275(1-3):1-10, DOI 10.1016/j.colsurfa.2005.10.061

Vargas JAV, Pagotto PC, dos Santos RG, Trevisan OV (2013) Determination of dispersion coefficient in carbonate rock using computed tomography by matching in situ concentration curves. In: SPE Annual Technical Conference and Exhibition, International Symposium of the Society of Core Analysts, pp SCA2013-053

Yousef AA, Al-Saleh S, Al-Kaabi A, Al-Jawfi M (2011) Laboratory investigation of the impact of injection-water salinity and ionic content on oil recovery from carbonate reservoirs. SPE Reservoir Evaluation and Engineering 14(5):578-593, DOI 10.2118/137634-PA

Yutkin M, Radke C, Patzek T (2021) Chemical compositions in salinity waterflooding of carbonate reservoirs: Theory. Transp Porous Med 136(2):411-429, DOI 10.1007/s11242-020-01517-7

Yutkin MP, Mishra H, Patzek TW, Lee J, Radke CJ (2018) Bulk and Surface Aqueous Speciation of Calcite: Implications for Low-Salinity Waterflooding of Carbonate Reservoirs. SPE Journal 23(01):084-101, DOI 10.2118/182829-PA

Zhang P, Austad T (2006) Wettability and oil recovery from carbonates: Effects of temperature and potential determining ions. Colloids and Surfaces A: Physicochemical and Engineering Aspects 279(1-3):179-187, DOI 10.1016/j.colsurfa.2006. 01.009

Zhang P, Tweheyo MT, Austad T (2007) Wettability alteration and improved oil recovery by spontaneous imbibition of seawater into chalk: Impact of the potential determining ions $\mathrm{Ca}_{2}{ }^{+}, \mathrm{Mg}_{2}{ }^{+}$, and $\mathrm{SO}_{4}{ }^{2-}$. Colloids and Surfaces A: Physicochemical and Engineering Aspects 301(1-3):199-208, DOI 10.1016/j.colsurfa.2006.12.058 

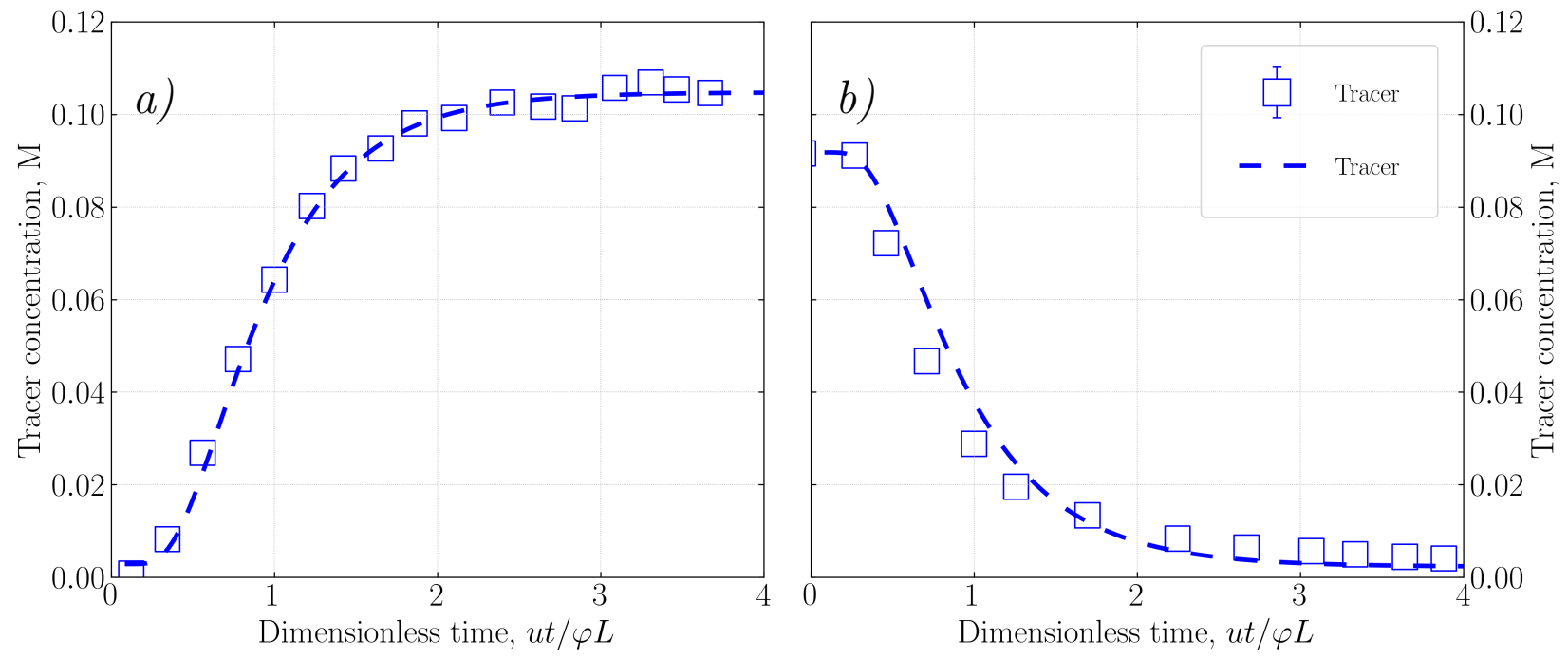

Figure 1: Tracer breakthrough analysis. (a) $\mathrm{Na}_{\infty}=10^{-3} \mathrm{M}, \mathrm{Na}_{0}=0.1 \mathrm{M}$. (b) $\mathrm{Na}_{\infty}=0.1 \mathrm{M}, \mathrm{Na}_{0}=10^{-3} \mathrm{M}$. Blue open squares denote experimental data; blue lines denote transport-model calculations. Error bar in the legend indicates typical measurement error. 

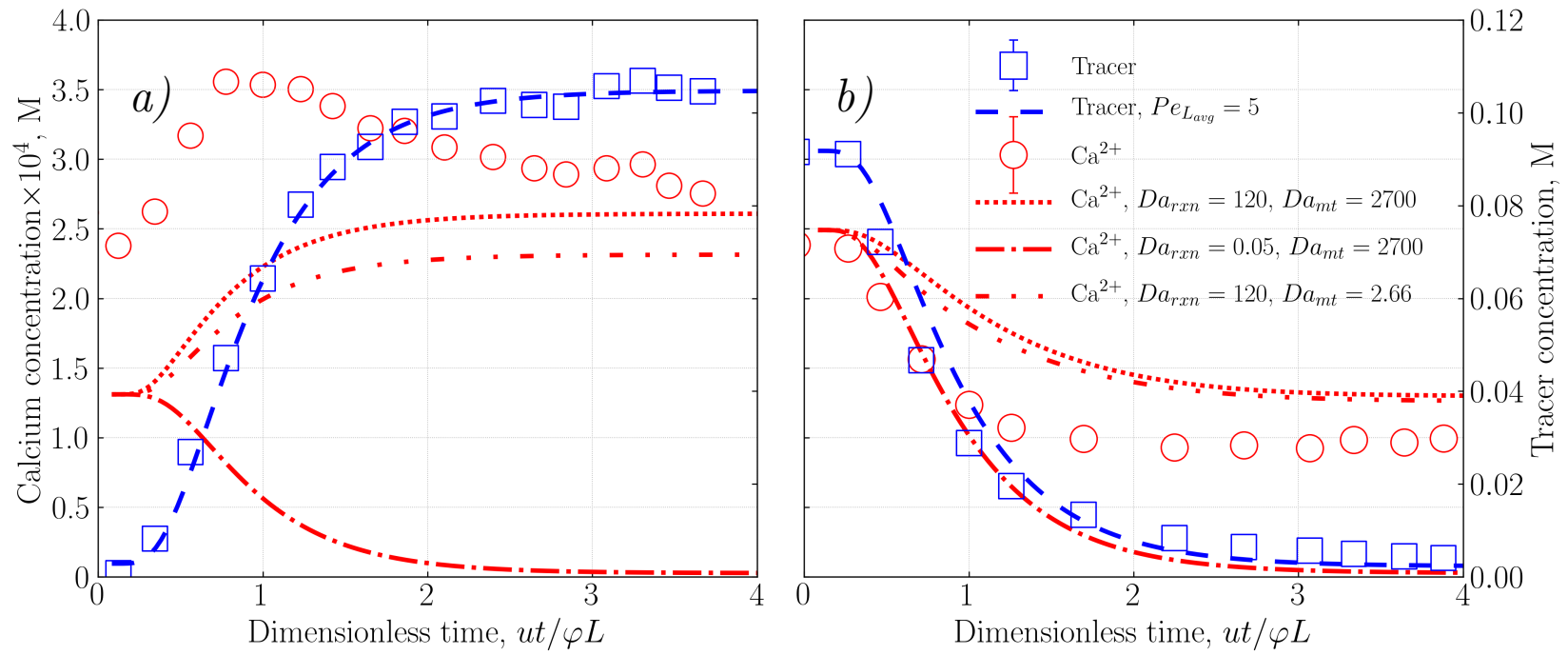

Figure 2: Concentration histories from core 1. (a) unloading or washout: $\mathrm{Na}_{\infty}=10^{-3} \mathrm{M}, \mathrm{Na}_{0}=0.1 \mathrm{M}, \mathrm{Ca}_{\mathrm{Na}}^{\mathrm{eq}}=$ $0.123 \mathrm{mM}, \mathrm{Ca}_{\mathrm{Na}_{0}}^{\mathrm{eq}}=0.225 \mathrm{mM}$. (b) loading: $\mathrm{Na}_{\infty}=0.1 \mathrm{M}, \mathrm{Na}_{0}=10^{-3} \mathrm{M}, \mathrm{Ca}_{\mathrm{Na}_{\infty}}^{\mathrm{eq}}=0.225 \mathrm{mM}, \mathrm{Ca}_{\mathrm{Na}_{0}}^{\mathrm{eq}}=0.123 \mathrm{mM}$. Open symbols denote experimental data; lines denote transport model calculations. Blue dashed lines correspond to tracer theory. Red lines denote calcium concentrations calculated using different assumptions: dotted line $-D a_{r x n}=$ 120, $D a_{m t}=2700$; dot dashed line $-D a_{r x n}=0.05, D a_{m t}=2700$; double dot dashed line $-D a_{r x n}=120, D a_{m t}=2.66$. Error bars in the legend indicate typical measurement error. See Table 1 for other details. 


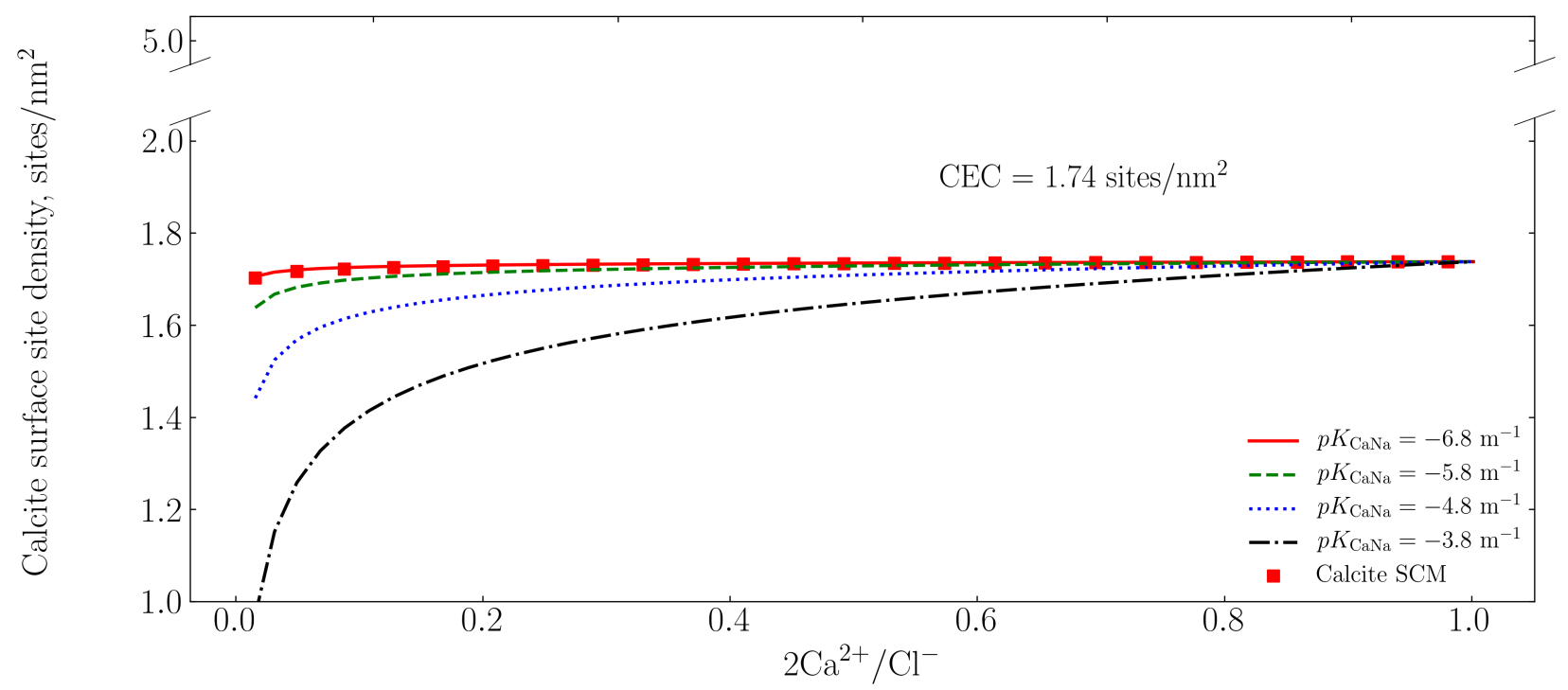

Figure 3: Calcium adsorption isotherms at variable salinity obtained from ion-exchange equilibria (lines) and calcite surface comlexation model (SCM, red closed squares) at a fixed adsorption sites density (or $C E C$ ) of 1.74 sites $/ \mathrm{nm}^{2}$. Line styles denote different ion-exchange equilibrium constants. Closed red squares are results from SCM (Yutkin et al., 2018). 

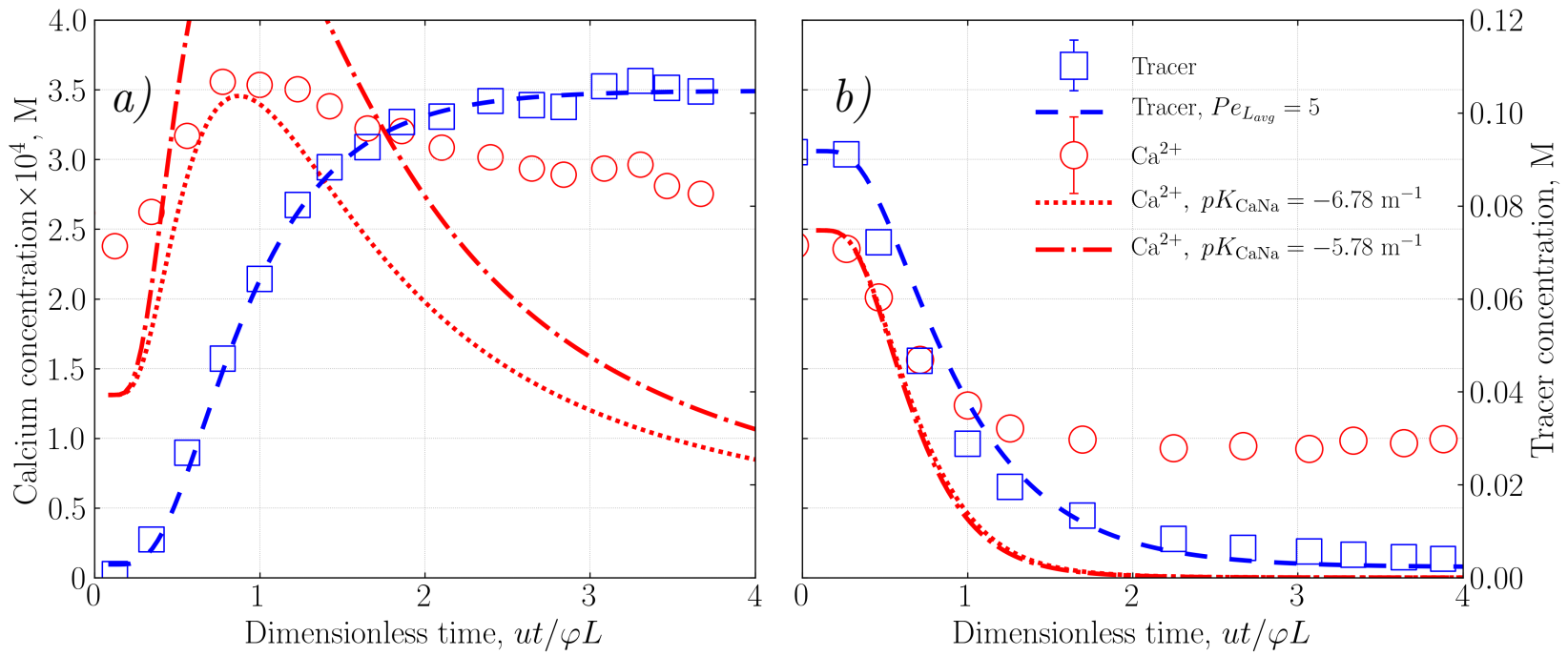

Figure 4: Concentration histories from core 1. (a) unloading or washout: $\mathrm{Na}_{\infty}=10^{-3} \mathrm{M}, \mathrm{Na}_{0}=0.1 \mathrm{M}, \mathrm{Ca}_{\mathrm{Na}}^{\mathrm{eq}}=$ $0.123 \mathrm{mM}, \mathrm{Ca}_{\mathrm{Na}_{0}}^{\mathrm{eq}}=0.225 \mathrm{mM}$. (b) loading: $\mathrm{Na}_{\infty}=0.1 \mathrm{M}, \mathrm{Na}_{0}=10^{-3} \mathrm{M}, \mathrm{Ca}_{\mathrm{Na} a_{\infty}}^{\mathrm{eq}}=0.225 \mathrm{mM}, \mathrm{Ca}_{\mathrm{Na}_{0}}^{\mathrm{eq}}=0.123 \mathrm{mM}$. Open symbols denote experimental data; lines denote transport-model calculations. Blue dashed lines correspond to tracer theory. Red lines denote calcium concentrations calculated using different assumptions: dotted line $-p K_{\mathrm{CaNa}}=-6.78$ $\mathrm{m}^{-1}$; dot dashed line $-p K_{\mathrm{CaNa}}=-5.78 \mathrm{~m}^{-1}$. Error bars in the legend indicate typical measurement error. See Table 1. 

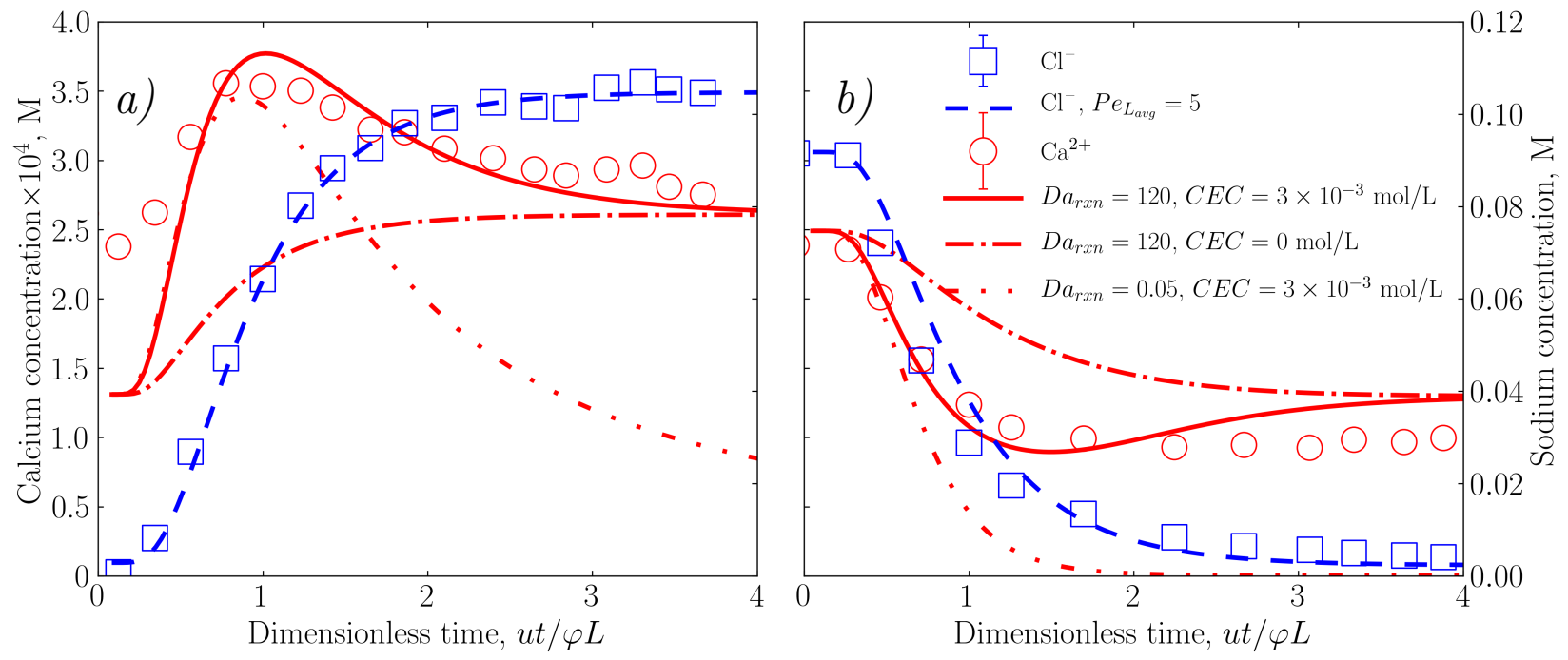

Figure 5: Concentration histories from core 1. (a) unloading or washout: $\mathrm{Na}_{\infty}=10^{-3} \mathrm{M}, \mathrm{Na}_{0}=0.1 \mathrm{M}, \mathrm{Ca}_{\mathrm{Na}}^{\mathrm{eq}}=$ $0.123 \mathrm{mM}, \mathrm{Ca}_{\mathrm{Na}_{0}}^{\mathrm{eq}}=0.225 \mathrm{mM}$. (b) loading: $\mathrm{Na}_{\infty}=0.1 \mathrm{M}, \mathrm{Na}_{0}=10^{-3} \mathrm{M}, \mathrm{Ca}_{\mathrm{Na}}^{\mathrm{eq}}=0.225 \mathrm{mM}, \mathrm{Ca}_{\mathrm{Na}_{0}}^{\mathrm{eq}} n=0.123 \mathrm{mM}$. Open symbols denote experimental data; lines denote transport model calculations: red solid lines: $\mathrm{Ca}^{2+}$; blue dashed lines: $\mathrm{Na}^{+} ; \mathrm{Cl}^{-}$was not measured in this experiment; red dot dashed line: $\mathrm{Ca}^{2+}$ for the model without ion-exchange but with fast dissolution, and red double-dot dashed lines: $\mathrm{Ca}^{2+}$ for the model with slow dissolution and ion exchange. Error bars in the legend indicate maximal measurement error. See Table 1. 

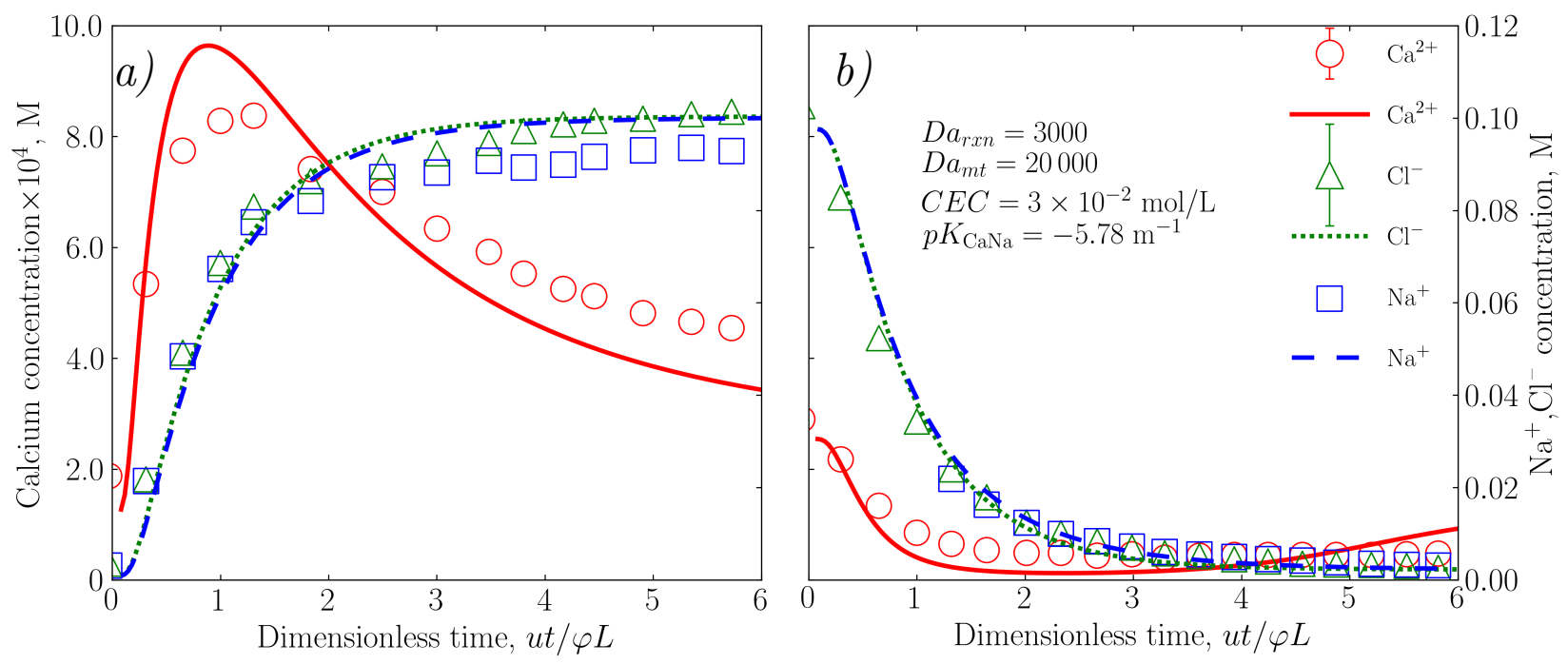

Figure 6: Concentration histories from core 2. (a) unloading or washout: $\mathrm{Na}_{\infty}=10^{-3} \mathrm{M}, \mathrm{Na}_{0}=0.1 \mathrm{M}, \mathrm{Ca}_{\mathrm{Na}}^{\mathrm{eq}}=$ $0.123 \mathrm{mM}, \mathrm{Ca}_{\mathrm{Na}_{0}}^{\mathrm{eq}}=0.225 \mathrm{mM}$. (b) loading: $\mathrm{Na}_{\infty}=0.1 \mathrm{M}, \mathrm{Na}_{0}=10^{-3} \mathrm{M}, \mathrm{Ca}_{\mathrm{Na}_{\infty}}^{\mathrm{eq}}=0.225 \mathrm{mM}, \mathrm{Ca}_{\mathrm{Na}_{0}}^{\mathrm{eq}}=0.123 \mathrm{mM}$. Open symbols denote experimental data; lines denote transport model calculations: red solid lines: $\mathrm{Ca}^{2+}$; blue dashed lines: $\mathrm{Na}^{+}$; green dotted lines: $\mathrm{Cl}^{-}$; red dot dashed lines: $\mathrm{Ca}^{2+}$ for the model without ion exchange but with fast dissolution, and red double dot dashed lines: $\mathrm{Ca}^{2+}$ for the model with slow dissolution and ion exchange. Error bars in the legend indicate maximal measurement error. See Table 2. 

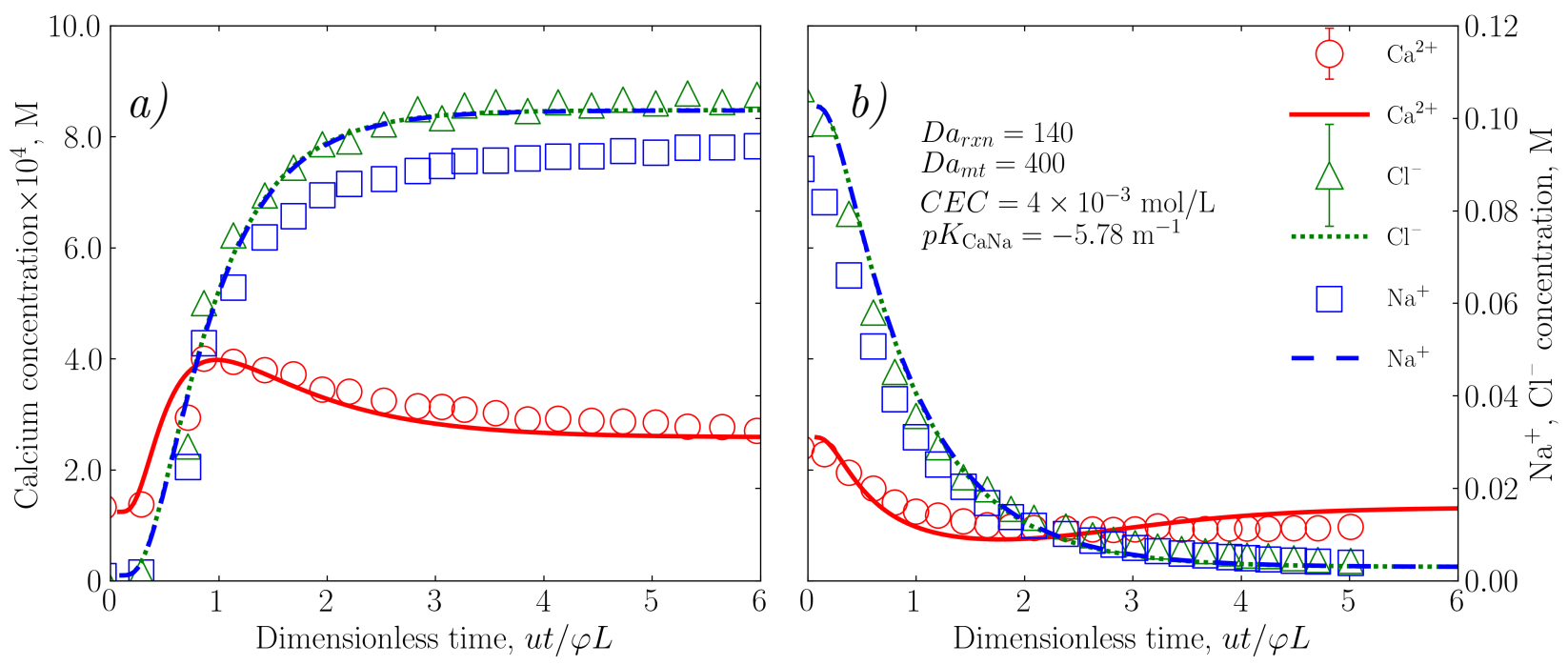

Figure 7: Concentration histories from core $3(50 \mathrm{~mL} / \mathrm{min})$. (a) unloading or washout: $\mathrm{Na}_{\infty}=10^{-3} \mathrm{M}, \mathrm{Na}_{0}=0.1 \mathrm{M}$, $\mathrm{Ca}_{\mathrm{Na}_{\infty}}^{\mathrm{eq}}=0.123 \mathrm{mM}, \mathrm{Ca}_{\mathrm{Na}_{0}}^{\mathrm{eq}}=0.225 \mathrm{mM}$. (b) loading: $\mathrm{Na}_{\infty}=0.1 \mathrm{M}, \mathrm{Na}_{0}=10^{-3} \mathrm{M}, \mathrm{Ca}_{\mathrm{Na}_{\infty}}^{\mathrm{eq}}=0.225 \mathrm{mM}, \mathrm{Ca}_{\mathrm{Na}_{0}}^{\mathrm{eq}}=$ $0.123 \mathrm{mM}$. Open symbols denote experimental data; lines denote transport model calculations: red solid lines: $\mathrm{Ca}^{2+}$; blue dashed lines: $\mathrm{Na}^{+}$; green dotted lines: $\mathrm{Cl}^{-}$; red double-dot-dashed lines: $\mathrm{Ca}^{2+}$ for model without ion exchange. Error bars in the legend indicate maximal measurement error. See Table 3. 

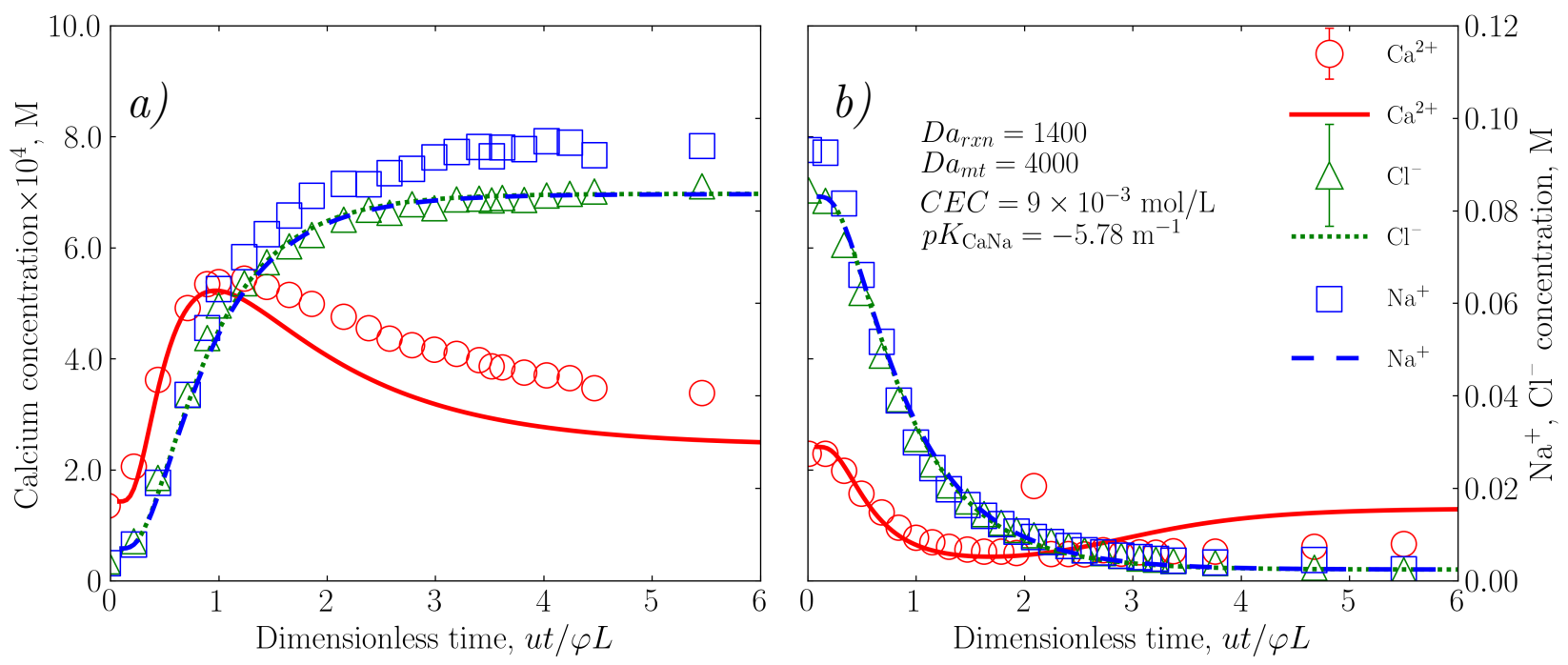

Figure 8: Concentration histories from core $3(5 \mathrm{~mL} / \mathrm{min})$. (a) unloading or washout: $\mathrm{Na}_{\infty}=10^{-3} \mathrm{M}, \mathrm{Na}_{0}=0.1 \mathrm{M}$, $\mathrm{Ca}_{\mathrm{Na}_{\infty}}^{\mathrm{eq}}=0.123 \mathrm{mM}, \mathrm{Ca}_{\mathrm{Na} 0}^{\mathrm{eq}}=0.225 \mathrm{mM}$. (b) loading: $\mathrm{Na}_{\infty}=0.1 \mathrm{M}, \mathrm{Na}_{0}=10^{-3} \mathrm{M}, \mathrm{Ca}_{\mathrm{Na}}^{\mathrm{eq}}=0.225 \mathrm{mM}, \mathrm{Ca}_{\mathrm{Na}_{0}}^{\mathrm{eq}}=$ $0.123 \mathrm{mM}$. Open symbols denote experimental data; lines denote transport model calculations: red solid lines: $\mathrm{Ca}^{2+}$; blue dashed lines: $\mathrm{Na}^{+}$; green dotted lines: $\mathrm{Cl}^{-}$; red double-dot-dashed lines: $\mathrm{Ca}^{2+}$ for model without ion exchange. Error bars in the legend indicate maximal measurement error. See Table 4. 

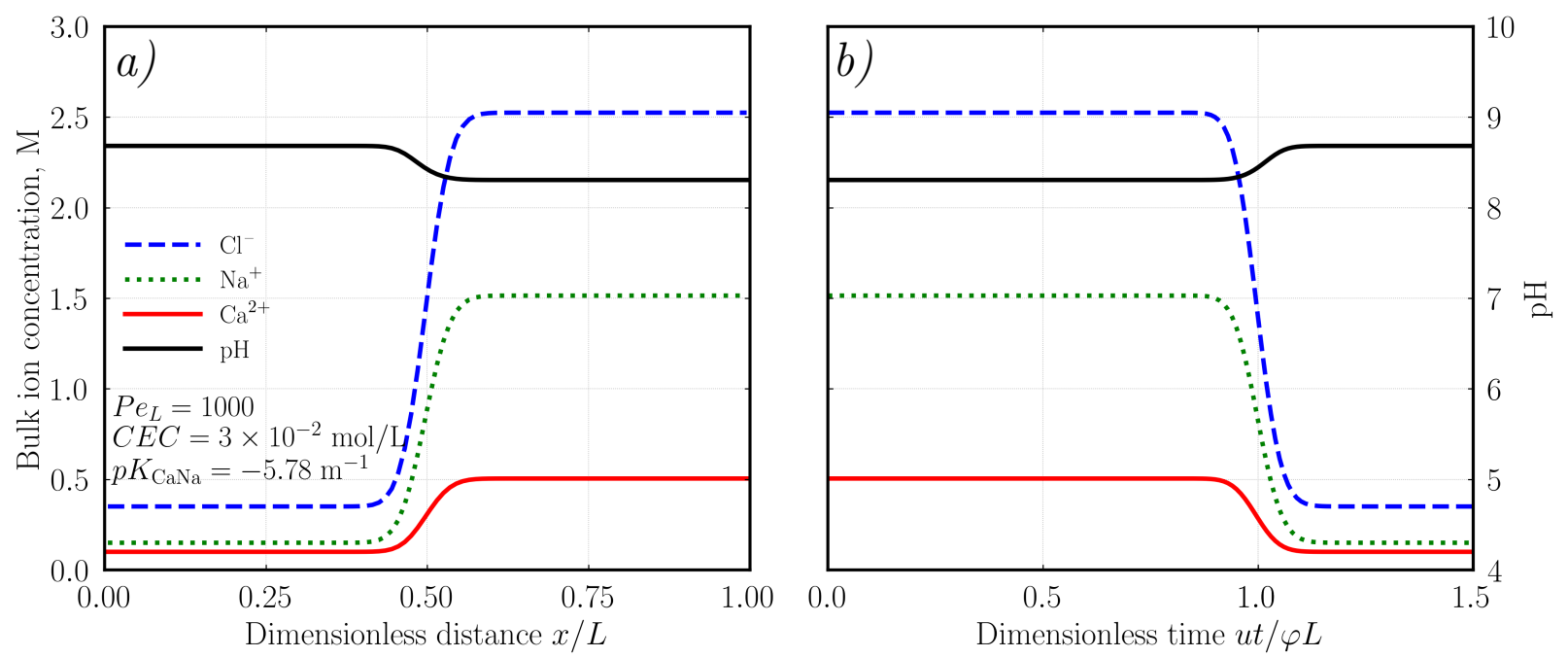

Figure 9: (a) Predicted concentration profiles and (b) concentration histories for the following injection sequence: $\mathrm{Na}_{\infty}$ $=1.5 \mathrm{M}, \mathrm{Na}_{0}=0.15 \mathrm{M}, \mathrm{Ca}_{\infty}^{2+}=0.5 \mathrm{M}, \mathrm{Ca}_{0}^{2+}=0.05 \mathrm{M}, \mathrm{Cl}_{\infty}^{-}=2.5 \mathrm{M}, \mathrm{Cl}_{0}^{-}=0.25 \mathrm{M}$. Red solid lines: $\mathrm{Ca}^{2+}$; blue dashed lines: $\mathrm{Na}^{+}$; green dotted lines: $\mathrm{Cl}^{-}$; black solid lines: $\mathrm{pH}$. $P e_{L}=1000, C E C=3 \times 10^{-2} \mathrm{~mol} / \mathrm{L}, p K_{\mathrm{CaNa}}=-5.78 \mathrm{~m}^{-1}$. 

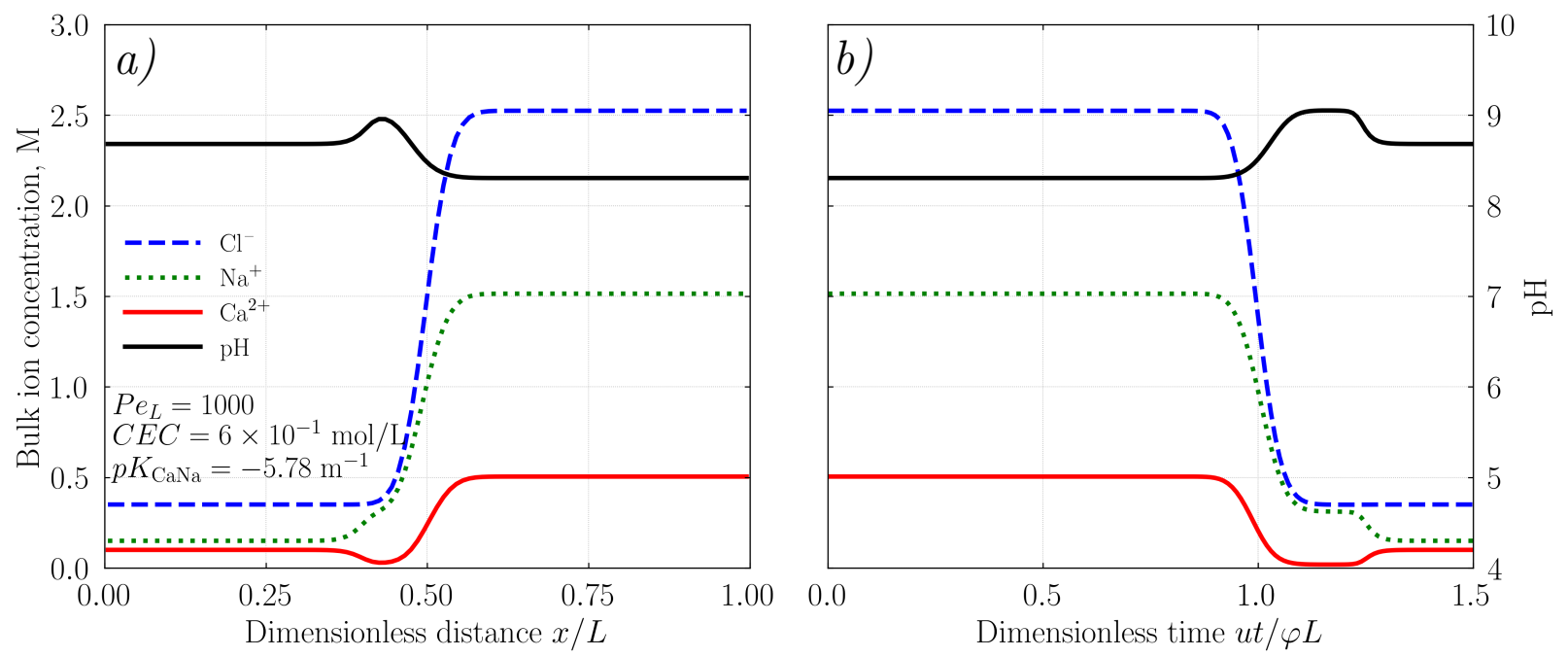

Figure 10: (a) Predicted concentration profiles and (b) concentration histories for the following injection sequence: $\mathrm{Na}_{\infty}$ $=1.5 \mathrm{M}, \mathrm{Na}_{0}=0.15 \mathrm{M}, \mathrm{Ca}_{\infty}^{2+}=0.5 \mathrm{M}, \mathrm{Ca}_{0}^{2+}=0.05 \mathrm{M}, \mathrm{Cl}_{\infty}^{-}=2.5 \mathrm{M}, \mathrm{Cl}_{0}^{-}=0.25 \mathrm{M}$. Red solid lines: $\mathrm{Ca}^{2+}$; blue dashed lines: $\mathrm{Na}^{+}$; green dotted lines: $\mathrm{Cl}^{-}$; black solid lines: $\mathrm{pH}$. $P e_{L}=1000, C E C=6 \times 10^{-1} \mathrm{~mol} / \mathrm{L}, p K_{\mathrm{CaNa}}=-5.78 \mathrm{~m}^{-1}$. 

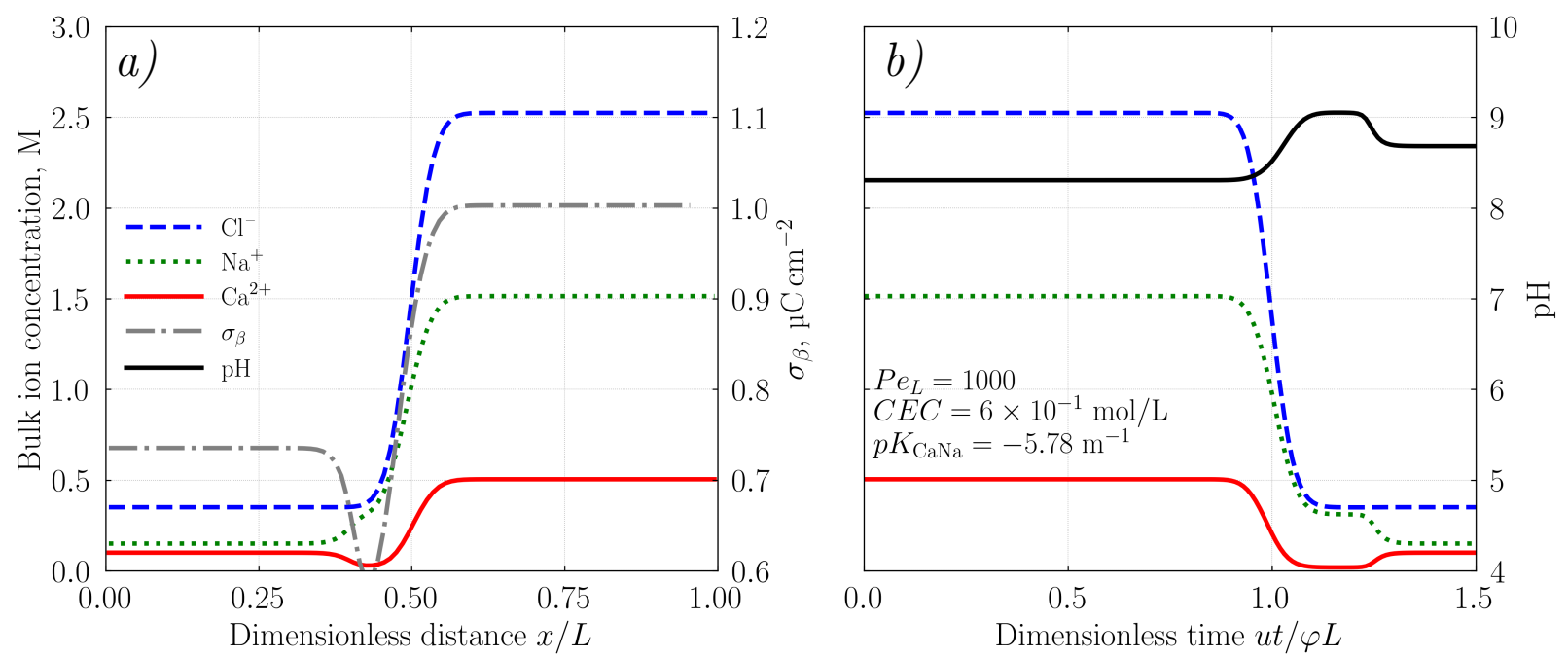

Figure 11: (a) Predicted concentration profiles and (b) concentration histories for the following injection sequence: $\mathrm{Na}_{\infty}$ $=1.5 \mathrm{M}, \mathrm{Na}_{0}=0.15 \mathrm{M}, \mathrm{Ca}_{\infty}^{2+}=0.5 \mathrm{M}, \mathrm{Ca}_{0}^{2+}=0.05 \mathrm{M}, \mathrm{Cl}_{\infty}^{-}=2.5 \mathrm{M}, \mathrm{Cl}_{0}^{-}=0.25 \mathrm{M}$. Red solid lines: $\mathrm{Ca}^{2+}$; blue dashed lines: $\mathrm{Na}^{+}$; green dotted lines: $\mathrm{Cl}^{-}$; black solid lines: $\mathrm{pH}$; gray dot dashed line: $\sigma_{\beta} . P e_{L}=1000, C E C=6 \times 10^{-1}$ $\mathrm{mol} / \mathrm{L}, p K_{\mathrm{CaNa}}=-5.78 \mathrm{~m}^{-1}$. 


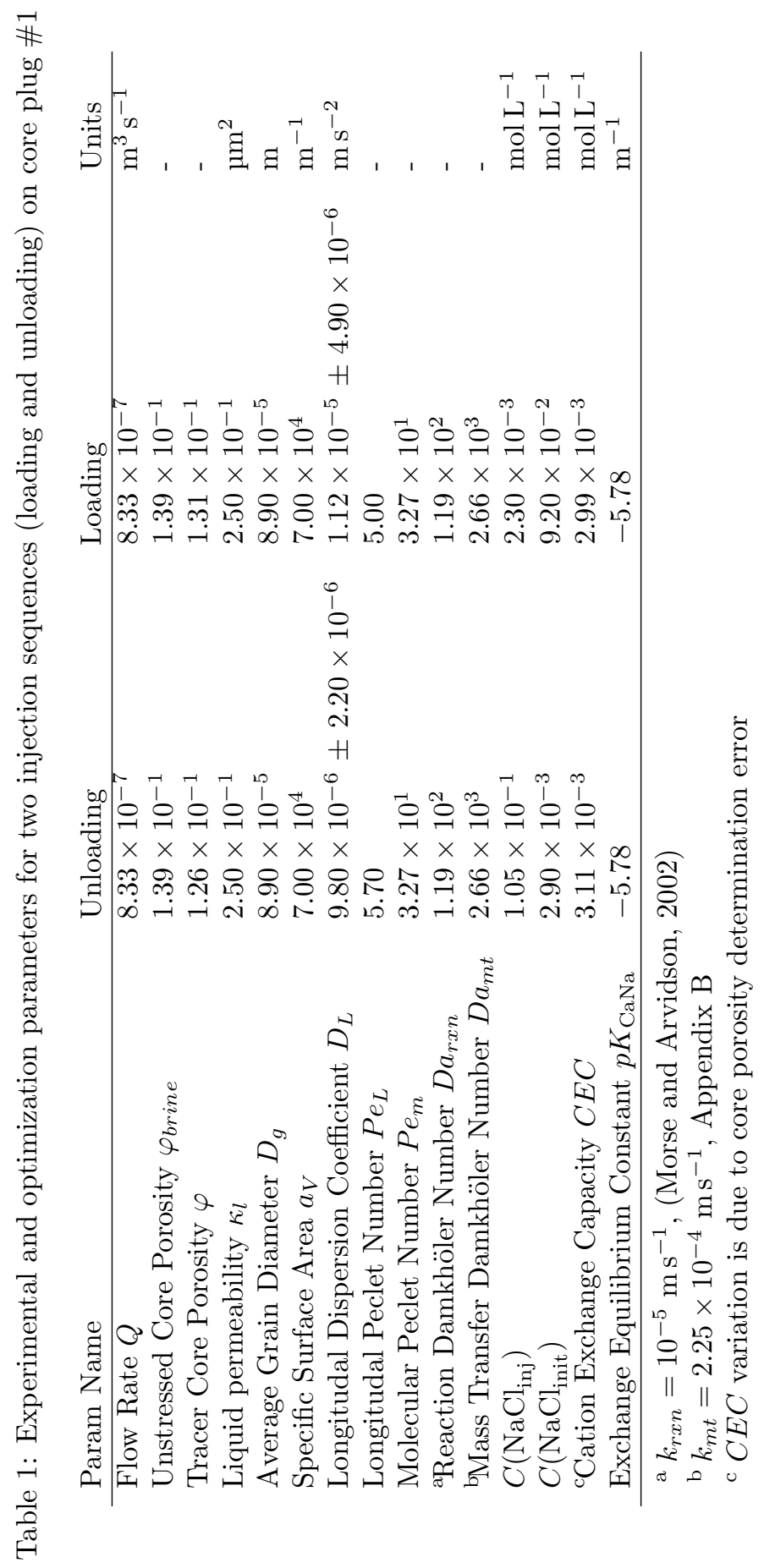




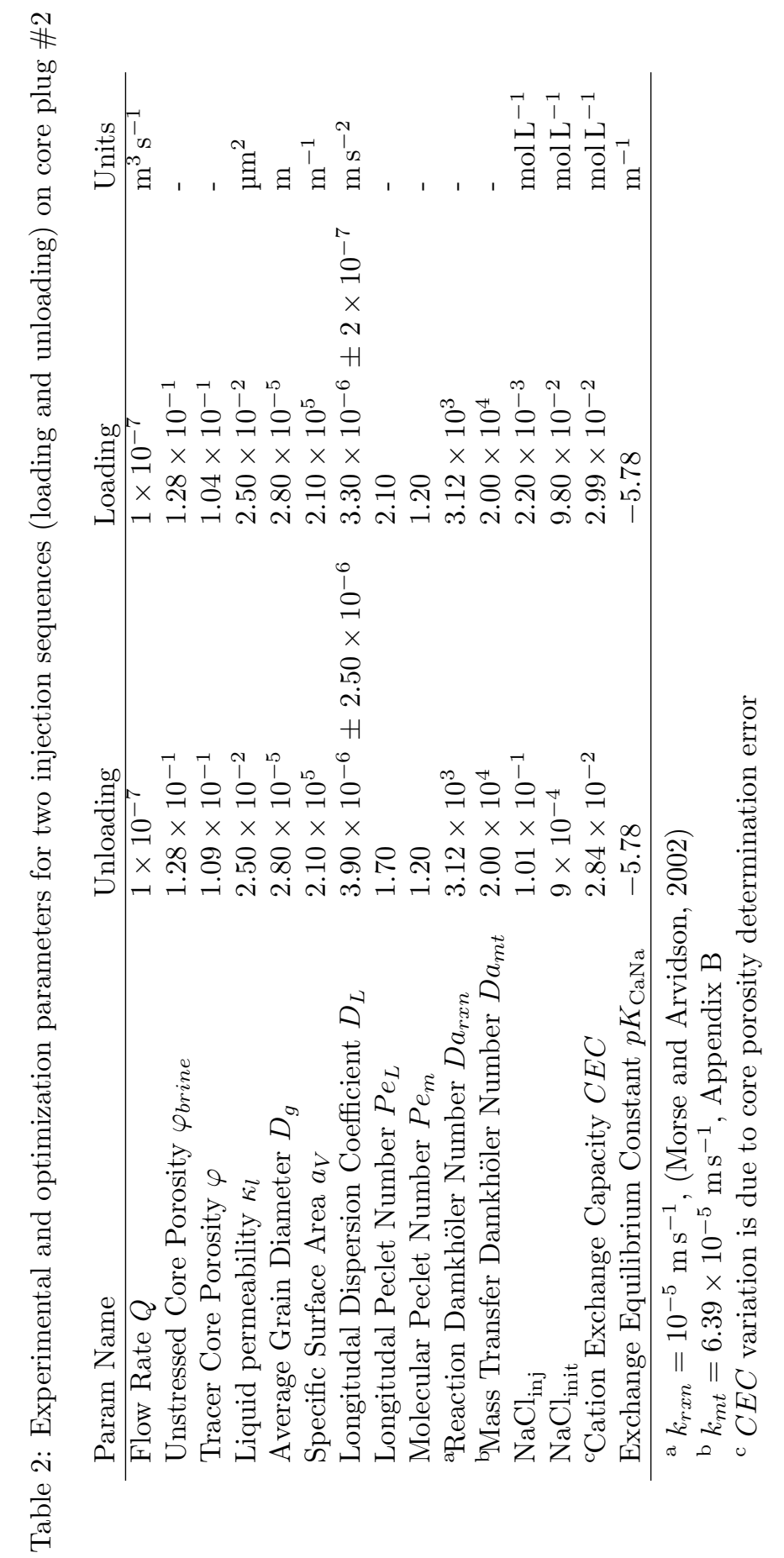




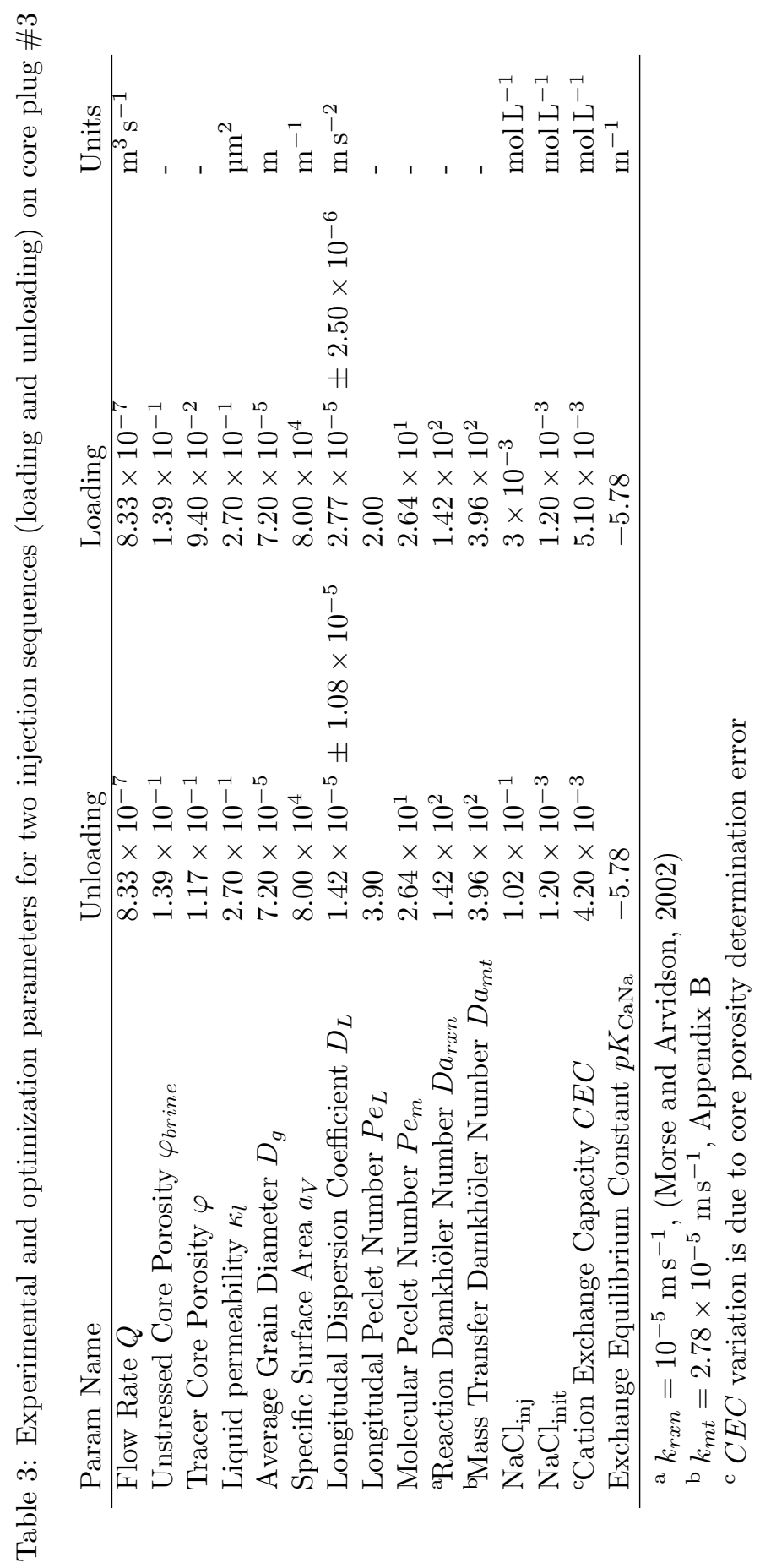




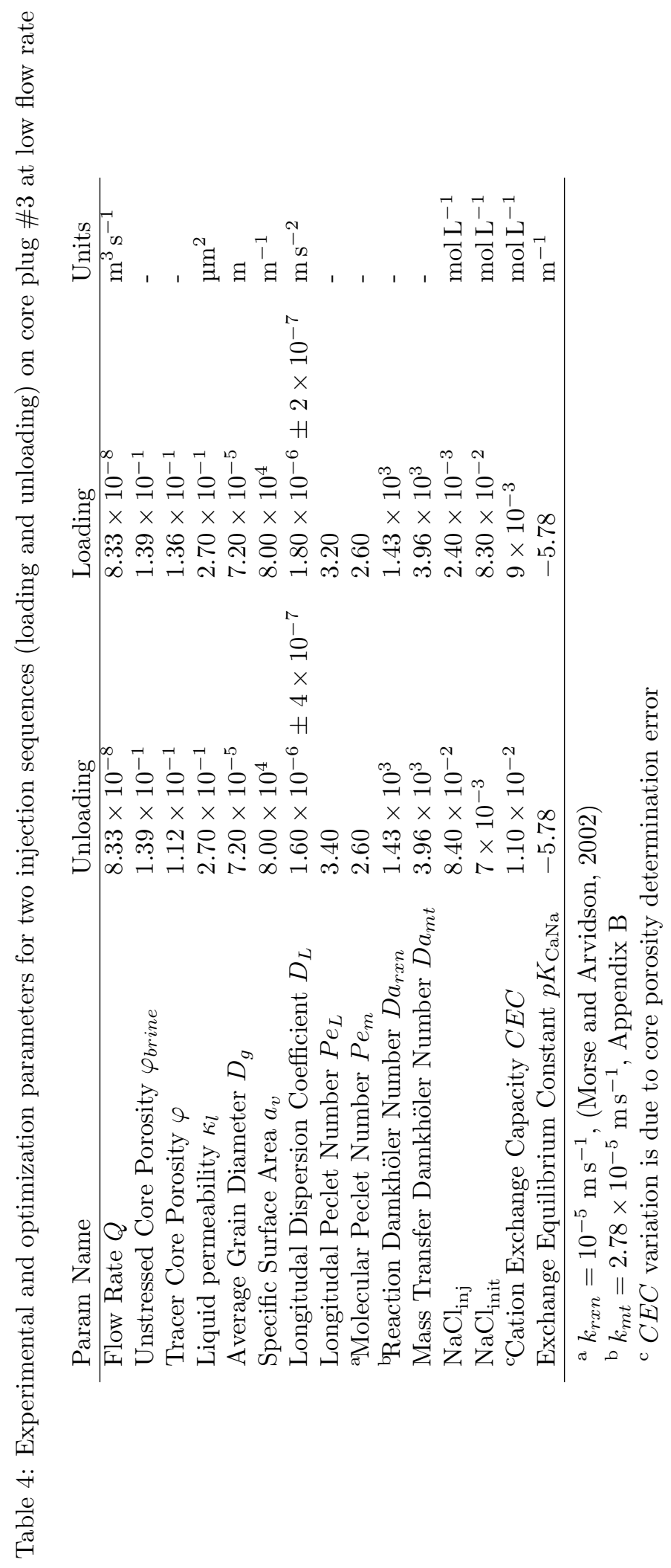


Table 5: Solution equilibrium reactions and equilibrium constants, $K_{r}(298 \mathrm{~K})$

\begin{tabular}{|c|c|c|c|}
\hline \# & Reaction & $p K_{r}$ & Units \\
\hline 1 & $\mathrm{CO}_{2}(\mathrm{~g}) \rightleftarrows \mathrm{CO}_{2}(\mathrm{aq})$ & 1.47 & $\mathrm{~mol} \mathrm{~L}^{-1} \mathrm{~atm}^{-1}$ \\
\hline 2 & $\mathrm{CO}_{2}(\mathrm{aq})+\mathrm{H}_{2} \mathrm{O} \rightleftarrows \mathrm{H}_{2} \mathrm{CO}_{3}$ & 2.59 & - \\
\hline 3 & $\mathrm{H}_{2} \mathrm{CO}_{3} \rightleftarrows \mathrm{H}^{+}+\mathrm{HCO}_{3}^{-}$ & 3.76 & $\mathrm{~mol} \mathrm{~L}^{-1}$ \\
\hline 4 & $\mathrm{HCO}_{3}{ }^{-} \rightleftarrows \mathrm{H}^{+}+\mathrm{CO}_{3}{ }^{2-}$ & 10.33 & $\mathrm{~mol} \mathrm{~L}^{-1}$ \\
\hline 5 & $\mathrm{H}_{2} \mathrm{O} \rightleftarrows \mathrm{H}^{+}+\mathrm{OH}^{-}$ & 14 & $\mathrm{~mol}^{2} \mathrm{~L}^{-2}$ \\
\hline 6 & $\mathrm{CaCO}_{3} \rightleftarrows \mathrm{Ca}^{2+}+\mathrm{CO}_{3}^{2-}$ & 8.48 & $\mathrm{~mol}^{2} \mathrm{~L}^{-2}$ \\
\hline 7 & $\mathrm{CaOH}^{+} \rightleftarrows \mathrm{Ca}^{2+}+\mathrm{OH}^{-}$ & 1.22 & $\mathrm{~mol} \mathrm{~L}^{-1}$ \\
\hline 8 & $\mathrm{CaHCO}_{3}{ }^{+} \rightleftarrows \mathrm{Ca}^{2+}+\mathrm{HCO}_{3}{ }^{-}$ & 1.11 & $\mathrm{~mol} \mathrm{~L}^{-1}$ \\
\hline 9 & $\mathrm{NaHCO}_{3} \rightleftarrows \mathrm{Na}^{+}+\mathrm{HCO}_{3}^{-}$ & -0.25 & $\mathrm{~mol} \mathrm{~L}^{-1}$ \\
\hline 10 & $\mathrm{NaCO}_{3}{ }^{-} \rightleftarrows \mathrm{Na}^{+}+\mathrm{CO}_{3}^{2-}$ & 1.27 & $\mathrm{~mol} \mathrm{~L}^{-1}$ \\
\hline
\end{tabular}


Table 6: Surface complexation reactions and corresponding equilibrium constants, $K_{s}(298 \mathrm{~K})$

\begin{tabular}{llrl}
\hline$\#$ & Reaction & $p K_{s}{ }^{\mathrm{a}}$ & Units \\
\hline $\mathrm{S}_{1}$ & $>\mathrm{Ca}^{+}+\mathrm{OH}^{-} \rightleftarrows>\mathrm{CaOH}$ & -2 & $\mathrm{~mol} \mathrm{~L}^{-1}$ \\
$\mathrm{~S}_{2}$ & $>\mathrm{Ca}^{+}+\mathrm{HCO}_{3}{ }^{-} \rightleftarrows>\mathrm{CaHCO}_{3}$ & -3 & $\mathrm{~L} \mathrm{~mol}^{-1}$ \\
$\mathrm{~S}_{3}$ & $2>\mathrm{Ca}^{+}+\mathrm{CO}_{3}{ }^{2-} \rightleftarrows(>\mathrm{Ca})_{2} \mathrm{CO}_{3}$ & 1 & $\mathrm{~L} \mathrm{~mol}^{-1}$ \\
$\mathrm{~S}_{4}$ & $>\mathrm{CO}_{3}{ }^{-}+\mathrm{H}^{+} \rightleftarrows>\mathrm{CO}_{3} \mathrm{H}$ & 2 & $\mathrm{~L} \mathrm{~mol}^{-1}$ \\
$\mathrm{~S}_{5}$ & $2>\mathrm{CO}_{3}{ }^{-}+\mathrm{Ca}^{2+} \rightleftarrows\left(>\mathrm{CO}_{3}\right)_{2} \mathrm{Ca}$ & -4 & $\mathrm{~L} \mathrm{~mol}^{-1}$ \\
$\mathrm{~S}_{6}$ & $>\mathrm{CO}_{3}{ }^{-}+\mathrm{Na}^{+} \rightleftarrows>\mathrm{CO}_{3} \mathrm{Na}$ & 0 & $\mathrm{~L} \mathrm{~mol}^{-1}$ \\
\hline
\end{tabular}

${ }^{a}$ modified from Yutkin et al. (2018) 


\section{Appendix A: Derivation of Tracer Mass-Balance}

The right side of Equation 1 of the main text for dispersion in porous medium contains two terms. At high $P e_{L}>50$, the contribution of the second term is negligible compared to the first, the breakthrough curve adopts a symetrical shape (Lake, 1989). Experimentally, this enables precise determination of the breakthrough time, and thus the medium porosity.

In this case, the time to reach $\widetilde{C}=0.5$ is the breakthrough time. However, in our experiments $P e_{L}$ is small (see Tables 1 -4). The contribution of the second term in Equation 1 is significant, and the breakthrough curve is asymmetric about the breakthrough time. Below we present a mass-balance analysis that justifies the approach we used for pore-volume calculation from the breakthrough curves.

Mass conservation through a packed column reads as

$$
\frac{d m}{d t}=C_{0} Q-C(t, x=L) Q
$$

where $m$ is tracer mass, $C_{0}$ is injected tracer concentration into a column, $C(t, x=L)$ tracer concentration at the column outlet, and $Q$ is volumetric flow. At $t=\infty$ the integral form becomes

$$
m(t=\infty)-m(t=0)=Q \int_{0}^{\infty}\left[C_{0}-C(t, x=L)\right] d t
$$

On the other hand $m(t=\infty)=\varphi A L C_{0}$, and $m(t=0)=\varphi A L C_{\infty}$, where $\varphi$ is porosity, $A$ is column cross-sectional area, and $L$ is column length. But $Q=\varphi L A / t_{b}$, where $t_{b}$ is breakthrough time, while $\varphi L A$ is pore volume. Substituting these definitions in Equation A.2 yields

$$
\frac{\varphi A L\left(C_{0}-C_{\infty}\right)}{Q}=\left(C_{0} C_{\infty}\right) t_{b}=\int_{0}^{\infty}\left[C_{0}-C(t, x=L)\right] d t
$$

For unknown $t_{b}$ the equality can be satisfied when the two areas (shaded and hatched-shaded, in Figure A.1) are equal. An algorithm based on the method of bisections was used in the model routine to calculate pore volume from tracer breakthrough. 
(a)

(b)
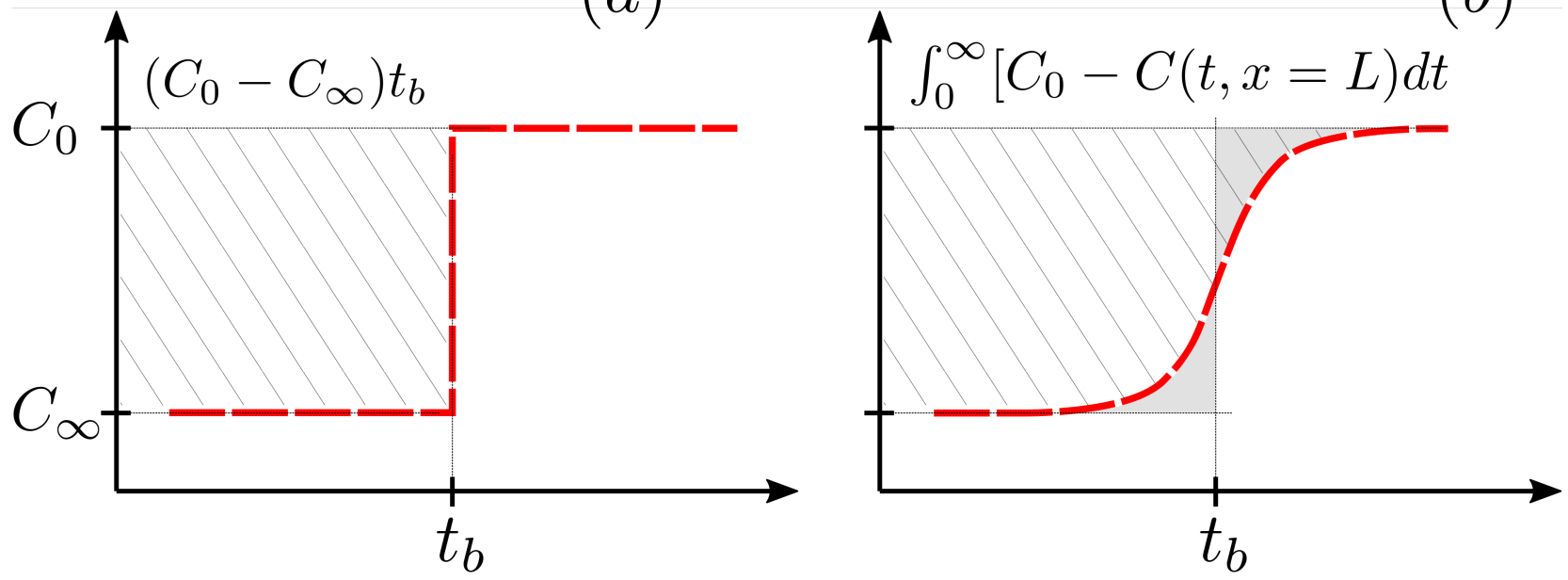

Figure A.1: Schematic demonstration of the tracer breakthrough curve mass balance. (a): non-dispersive tracer history is a step function. The white area on the right is equal to the cross-hatched area on the left. (b): dispersive tracer transport. Grey and cross-hatched-gray areas must be equal to satisfy mass balance. 


\section{Appendix B: Mass-Transfer Rate and Specific Surface Area Estimation}

Rexwinkel et al. (1997) summarizes experimental mass-transfer coefficients in packed beds at different molecular Péclet numbers $P e_{m}$. In our experiments with high flow rates $P e_{m}$ is of the order of $10^{2}$. From Rexwinkel et al. (1997, fig. 2 ) we find Sherwood number $(S h)$ of about 10 for high-flow-rate experimental conditions. Likewise, for low flow rate experiments, we find Sherwood numbers of 1, where Sherwood number is a dimensionless mass-transfer coefficient defined by

$$
S h=\frac{k_{m t} D_{g}}{D_{m}}
$$

where $D_{g}$ is average particle diameter, $\mathrm{m}, D_{m}$ is molecular diffusion coefficient $\left(10^{-9} \mathrm{~m}^{2} / \mathrm{s}\right) . D_{g}$ is obtained from $a_{V}$, such that $D_{g}=6 / a_{V}$. We estimate $a_{V}$ using the well-known Carmen-Kozeny expression (Bird et al., 2007).

$$
a_{V}^{2}=\frac{36}{150} \frac{\varphi^{3}}{(1-\varphi)^{2} \kappa}
$$

Here $\varphi$ is porosity, and $\kappa$ is brine permeability. For the $250-\mathrm{mD}$ core sample (Core 1 ) used in this work, $D_{g}$ is of the order of $10^{-5} \mathrm{~m}$. This gives a mass-transfer coefficient $\left(k_{m t} \approx 3.510^{-3} \mathrm{~m} / \mathrm{s}\right.$ for high flow rate and $k_{m t} \approx 3.510^{-4} \mathrm{~m} / \mathrm{s}$ for low flow rate.

\section{Appendix C: Experimental Data Attachments}

The SI pdf file contains enclosed experimental data.

File attachments: Data archive: 